\title{
Structural Change and Financing Constraints
}

\author{
Anna O. Ilyina and Roberto M. Samaniego*
}

February 26, 2011

\begin{abstract}
In a multi-industry growth model, firms require external funds to conduct productivityenhancing $R \& D$, and face financing constraints. The cost of research differs across industries, so that financing constraints hinder productivity growth in some industries more than in others. Equilibrium industry dynamics map into a differences-indifferences regression specification where industry growth depends on the interaction between country financial development and industry R\&D intensity. The paper provides a framework for interpreting several empirical results that rely on industry growth data in terms of R\&D-induced technology transfer, and identifies a new channel for finance to encourage aggregate growth: the reallocation of resources towards sectors with rapidly-expanding technological frontiers.
\end{abstract}

JEL Codes: G18, O14, O16, O33, O47.

Keywords : Financial development, industry growth, R\&D intensity, external finance dependence, convergence dynamics, structural change, differences-in-differences.

${ }^{*}$ We are grateful to seminar participants at several workshops and conferences for helpful comments. This paper should not be reported as representing the views of the IMF. The views expressed are those of the author(s) and do not necessarily represent those of the IMF or IMF policy. Anna Ilyina: International Monetary Fund, 700 19th St NW, Washington, DC 20431. Roberto Samaniego: Department of Economics, George Washington University, 2115 G St NW Suite 340, Washington, DC 20052. Tel: (202) 994-6153. Fax: (202) 994-6147. E-mail: roberto@gwu.edu. 


\section{Introduction}

The reallocation of resources across activities is thought to be a critical function of financial markets. Indeed, the impact of financial development on growth is known to vary across industries, providing evidence of this reallocation across industries. Notably, Rajan and Zingales (1998, henceforth RZ) show that financial development promotes disproportionately rapid growth in industries with a greater tendency to draw on external funds. However, finance-enabled reallocation may or may not play a role in the process of aggregate growth, depending on the characteristics of the favored industries. Ilyina and Samaniego (forthcoming) study the technological characteristics that might underpin the industry tendency to use external funds, finding that this tendency is linked to RED intensity. ${ }^{1}$ Thus, R\&D is a key ingredient in the process of finance-enabled reallocation across industries.

The finance-growth link has been modeled extensively, but mainly in a one-sector context. $^{2}$ A multisector model of the finance-growth nexus is desirable for several reasons. First, an explicit theoretical foundation for observed cross-industry differences in the financegrowth link can only be provided in a multi-sector model. Without such a foundation - based on the empirical relationships between the use of external finance and technological characteristics - it is difficult to interpret the results of industry growth regressions such as RZ. Second, a multisector framework is required to understand the aggregate implications of the industry reallocation induced by financial development. Without a theoretical framework, the empirical finding that financial development disproportionately encourages growth in some industries relative to others does not readily translate into an absolute statement about aggregate outcomes. Third, differences in growth across industries necessarily result in structural change, which can only be analyzed in a multisector framework.

This paper develops a multi-sector R\&D-based growth model that builds on the empirical link between the use of external finance and research intensity. The mechanism through which financing constraints affect growth combines productivity-enhancing R\&D and productivity-driven structural change. Agents raise external funds to pursue R\&D, which moves them closer to the world productivity frontier as in the one-sector model of Aghion, Howitt and Mayer-Foulkes (2005, henceforth AHM). Thus, the goal of R\&D is tech-

\footnotetext{
${ }^{1}$ Ilyina and Samaniego (forthcoming) also find it is not robustly related to several other technological characteristics such as labor intensity, human capital intensity, intangibles intensity, capital depreciation, the rate of embodied technical change.

${ }^{2}$ One-sector models include Greenwood and Jovanovic (1990), Bencivenga and Smith (1991), De la Fuente and Marín (1996), Khan (2001) Morales (2003) and Aghion, Howitt and Mayer-Foulkes (2005). Buera, Kaboski and Shin (2008) study the impact of financing constraints on GDP levels in a multisector model, but do not study industry growth nor structural change. Rancière and Tornell (2009) study the impact of systemic crises on sectors with different financial frictions.
} 
nology transfer. Industry differences in the productivity improvement obtained from each dollar of R\&D spending lead to equilibrium differences in desired research intensity and frontier productivity growth. Financing constraints are modeled as a borrowing limit that depends on an entrepreneur's wealth, as in Evans and Jovanovic (1989), and these limits may vary depending on the level of institutional development, which is a given in each country. ${ }^{3}$

In a "benchmark" economy, where financing constraints do not limit R\&D spending, optimal industry $\mathrm{R} \& \mathrm{D}$ is positively related to the growth rate of the industry productivity frontier. In financially constrained economies, R\&D investment depends on the distance to the frontier, and on whether financing constraints bind. A financially constrained economy may potentially converge to the benchmark economy in the long-run, displaying structural change driven by industry differences in productivity growth rates, as in Ngai and Pissarides (2007). However, unlike Ngai and Pissarides (2007), productivity growth rates are endogenous in our model.

The productivity growth rate of an industry can be decomposed into the growth rate of the productivity frontier, and the rate at which productivity converges to this frontier. Financing constraints slow convergence, and we show that convergence in R\&D-intensive industries is particularly sensitive. Thus, not only does financial development slow productivity growth by limiting productivity-enhancing R\&D: it particularly slows productivity growth in the industries with the most rapidly-growing technological frontiers. For reasonable parameters, financing constraints skew the composition of the economy towards industries with relatively slow-growing technological frontiers. As a result, the allocative function of financial markets encourages growth for two reasons in our multi-industry model: it allows the economy to devote more resources towards productivity growth, and it reallocates resources more rapidly towards the industries with the fastest-growing productivity frontiers.

The model provides an integrated framework that accounts for the main empirical finding of RZ - that more financially dependent industries grow relatively faster in financially developed economies - as well as the finding of Wurgler (2000) and Fisman and Love (2007) that financial development favors rapidly-growing industries, and the finding of Ilyina and Samaniego (forthcoming) that the same is true of R\&D-intensive industries. Indeed, the differences-in-differences regression specifications in these papers can be mapped into a second-order Taylor approximation to the equilibrium dynamics of the model economy. Thus, the results of these industry growth regressions can be interpreted as support for

\footnotetext{
${ }^{3}$ Acemoglu and Johnson (2005) argue that financial development is grounded in institutions that persist over a substantial period of time. Cohen and Levin (1989) and Ngai and Samaniego (2011) find that differences in the "yield" of a dollar of R\&D account for the bulk of observed industry differences in R\&D intensity. Aghion, Benerjee and Piketty (1999) show a financing constraint a-la Evans and Jovanovic (1989) can be viewed as an equilibrium outcome in an environment in which profits can be diverted at a cost.
} 
the main mechanisms of the model, and the interaction coefficients in those papers can be interpreted as measures of the impact of financial development on industry productivity growth differentials. Within the sample of Rajan and Zingales (1998), we find that raising financial development to the level of the most financially developed country (Japan) raises manufacturing productivity growth in the other countries by $0.5-1.5 \%$ annually.

The key parameter relating industry growth to productivity growth is the elasticity of substitution across goods. If the elasticity of substitution is more than one, then looser financing constraints lead to an accelerated reallocation of resources towards industries with rapidly growing productivity. However, if the elasticity of substitution is less than one, the opposite is the case. This underlines the importance not only of a multi-sector framework for analyzing the finance-growth link, but also the importance of general equilibrium analysis. For example, it might seem straightforward to infer that, if financial markets allocate resources efficiently, then financial development leads to a more rapid reallocation of resources towards industries with greater productivity growth, or towards industries where the cost of further productivity improvements is low, and such an inference might motivate a regression framework to study differences in industry growth. However, this inference ignores the impact of the demand side of the economy. Whether rapid productivity change leads the growth rate an industry to increase or to decrease relative to other industries depends on whether it produces a complement or a substitute to other goods.

As a result, our paper suggests a reinterpretation of empirical work based on industry growth data. First, in a world of finance-enabled, productivity-enhancing R\&D, the results of RZ, Fisman and Love (2007) and Ilyina and Samaniego (forthcoming) are arguably different facets of the same industry dynamics. Second, according to the model, the reason that RZ find that industry growth is disproportionately sensitive to financial development in industries that tend to draw on external finance is because these industries are highly research-intensive. If the disproportionate use of external finance were unrelated to $R \& D$ spending - which, by leading to productivity improvements, plays a key role in the process of economic growth - then the RZ finding might not obtain. Third, if the elasticity of substitution across goods were less than one, then the sign of the interaction coefficient in the RZ regression would be negative - even if financial development in fact does accelerate aggregate growth. The reason is that growth in industry $i$ relative to industry $j$ is equivalent to an increase in the share of GDP of $i$ relative to $j$. More rapid productivity growth in industry $i$ leads to an accelerated decline in the price of good $i$ in equilibrium, but whether or not this translates into an increase or a decrease in the share of expenditure on good $i$ depends on the elasticity of substitution. The value of the elasticity of substitution is a subject of some controversy and, in the context of broad sectors (manufacturing and services) is generally 
thought to be less than one, see Ngai and Pissarides (2007). However, we find evidence that this elasticity is greater than one at a more disaggregated level and within sectors. Thus, structural change leads more productive, more R\&D intensive and more external financedependent industries to grow as a share of the economy, and this process is accelerated by financial development.

These industry results have the following aggregate implications. In the long run, structurak change driven by productivity differences implies that the economy eventually becomes more and more specialized so that, in the simplest version of the model, one industry grows to dominate the economy in the limit. ${ }^{4}$ We refer to this industry as the "limiting industry." As a result, aggregate income in a less financially developed economy fails to converge to that in the benchmark economy if financial development is so low that the limiting industry is itself financially constrained: over time, the aggregate impact of other industries diminishes. If the elasticity of substitution exceeds one, the limiting industry turns out to be the one with the fastest rate of expansion of the technological frontier - which is also the most dependent on external finance. Again, we underline that the aggregate impact of the allocative role of financial markets depends crucially on preference parameters, and not only on productivity and other supply-side factors.

To assess whether the mechanisms in the model can generate patterns of structural change similar to those in the data, we calibrate the model economy to match research patterns in the United States (consistent with the RZ methodology of measuring industry technological characteristics in a relatively undistorted environment), and introduce financing frictions to generate industry growth rates. We calibrate financing constraints by matching crosscountry differences in R\&D spending, and regress model-generated industry growth rates on interactions of R\&D intensity and financial development. We obtain economically and statistically significant interaction coefficients if financing constraints account for about a third of cross-country R\&D spending differences, and if initial conditions are not so dispersed as to void the relevance of the Taylor approximation underlying the regression specification.

Section $I I$ introduces the model, and Sections $I I I$ and $I V$ characterize the equilibrium dynamics of aggregate growth and of industry growth respectively. Section $V$ calibrates the model economy. Section VI suggests directions for future research. The technical appendix reports evidence in support of certain assumptions and predictions of the model, and a discussion of the ability of the model to account for a well-known pattern of structural change, the "stages of diversification" identified by Imbs and Wacziarg (2003).

\footnotetext{
${ }^{4}$ Given the complexity of characterizing structural change in a multisector general equilibrium context, we focus on this version of the model for the sake of tractability. However, in the technical appendix we discuss a version of the model in which the limiting structure of the economy contains more than one industry yet the main results continue to hold.
} 


\section{Economic Environment}

We present a quality-ladder model with many industries. It generalizes the one-sector model in AHM to a multi-industry context, and features the mechanism of productivity-driven structural change studied in Ngai and Pissarides (2007).

Time is indexed by $t \in \mathbb{N}$. The model economy produces $J \in \mathbb{N}$ types of final good. The world productivity frontier $A_{j t}^{*}$ for the production of each good $j$ expands over time by an industry-specific factor $g_{j}>1$, so that $A_{j, t+1}^{*}=A_{j t}^{*} g_{j}$. Knowledge spillovers are unlimited in the sense that the technological frontier in industry $j$ is available to firms in all countries: however, each firm can approach the technological frontier only by means of R\&D. Thus, R\&D determines the firm's ability to absorb knowledge, as found by Cohen and Levinthal (1990) and Griffith, Redding and Van Reenen (2004).

\section{A Economic Agents and Firms}

In each period, a cohort of economic agents of mass 1 is born. Agents live for two periods, enjoying consumption $c_{t}$ and using labor $l_{t} \in\{0,1\}$ in each period $t$. The discount factor is $\rho<1$. There are $J>1$ industries that produce final goods. If $c_{j t}$ is consumption of each, then:

$$
c_{t}=\left[\sum_{j=1}^{J} \xi_{j} c_{j t}^{\frac{\varepsilon-1}{\varepsilon}}\right]^{\frac{\varepsilon}{\varepsilon-1}}, \sum_{j=1}^{J} \xi_{j}=1
$$

where $\varepsilon>0, \varepsilon \neq 0$ is the elasticity of substitution across goods. Let $q_{j t}$ be the price of good $j$. The budget constraint for a young agent born at date $t$ is:

$$
\sum_{j} q_{j t} c_{j t}+\left(b_{t}-S_{t}\right) \leq w_{t}
$$

where $w_{t}$ is a competitive wage. Agents save or borrow using bonds $b_{t}$. The interest rate is $r_{t}$. Agents may also invest in future income by means of R\&D spending $S_{t}$.

Old agents choose to become workers, entrepreneurs or researchers. The budget constraint of an old agent who was born on date $t$ is:

$$
\sum_{j} q_{j, t+1} c_{j, t+1} \leq\left(b_{t}-S_{t}\right)\left(1+r_{t+1}\right)+X\left(\theta, S_{t}, \lambda_{t}\right)
$$

where $\theta \in\{W, E, R\}$ represents occupational choice. $W$ represents the choice of being a worker when old, whereas $E$ represents entrepreneurship and $R$ represents research. $X\left(\theta, S_{t}, \lambda_{t}\right)$ represents income based on occupational choice, and $\lambda_{t}$ is a random variable that represents 
uncertainty that an agent might face in any given occupation. If an agent chooses to work when old, income $X\left(W, S_{t}, \lambda_{t}\right)=w_{t+1}$. Income for entrepreneurs and for researchers is discussed below. We assume that agents do not know the realization of $\lambda_{t}$ until after they have selected their occupation, but may choose consumption, savings and $S_{t}$ optimally at the end of period $t$ after knowing this realization. The assumption of optimal savings conditional on occupational choice ensures that there is no inefficiency due to the timing of events in the model, but does not affect the results otherwise.

Thus, an agent born in period $t$ solves

$$
\max _{\substack{b_{t}, c_{t}, c_{t+1}, S_{t}, \theta \in\{W, E, R\}}}\left\{c_{t}+\rho E_{t} c_{t+1}\right\}
$$

subject to (1), (2) and (3). This functional form for utility abstracts from risk aversion, focusing the analysis on the relative profitability of different activities. Henceforth, the wage $w_{t}$ is normalized to one, so all prices are expressed relative to the wage. Labor and product markets are competitive. With linear utility, $\left(1+r_{t}\right)=\rho^{-1}$, and agents are indifferent regarding the date of consumption.

\section{B Production}

\section{B.1 Final goods}

Production of any final good $j$ requires labor $l_{j t}$ and a continuum of intermediate goods $x_{j t}(i)$, where $i \in[0,1]$. Output at a firm in any industry $j$ is

$$
y_{j t}=l_{j t}^{\alpha_{l}} \int_{0}^{1} A_{j t}(i)^{1-\alpha_{x}} x_{j t}(i)^{\alpha_{x}} d i,
$$

where $A_{j t}(i)$ is the productivity with which the firm uses intermediate good $i$. A firm's productivity is defined as:

$$
A_{j t}=\int_{0}^{1} A_{j t}(i) d i .
$$

When a new firm is established, it randomly imitates a firm in that industry that was active in the previous period, as in Luttmer (2007). However, it need not be that $A_{j t}(i)=A_{j, t-1}(i)$, because of the possibility of research that builds on the knowledge of the imitated firm. Define $a_{j t}=A_{j t} / A_{j t}^{*}$ as the productivity gap in industry $j$, its position in terms of productivity relative the frontier. 


\section{B.2 Intermediate goods}

Intermediate goods need to be customized to enable a given firm to use them at the frontier level of efficiency. Conditional on success in customizing a given variety $i$, a researcher who is matched with a firm can produce any quantity $x_{j t}(i)$ of the customized good using one unit of good $j$ per unit of intermediate. ${ }^{5}$ The customized intermediate good can then be used at the frontier efficiency $A_{j t}^{*}$. In the absence of innovation, variety $i$ will be used at the previous period's productivity level $A_{j, t-1}(i)$. The market for customized intermediates $i$ is described below: the price of intermediate $i$ in industry $j$ is $p_{j t}(i)$.

There are immediate (though imperfect) spillovers of new knowledge, so that the entrepreneur (or anyone else) may produce copies of a customized intermediate at cost $\chi>1$ in units of good $j$ (we can think of $\chi-1$ as a cost of imitation). Thus, researchers will charge the limit price $p_{j t}(i)=\chi q_{j t}$. As for varieties $i$ without successful innovation in the current period, production takes place under perfect competition, also at price $p_{j t}(i)=\chi q_{j t}$. Then, profits from the production of good $j$ are:

$$
\Pi_{j t}^{E}=\max _{l_{j t}, x_{j t}}\left\{q_{j t} y_{j t}-w_{t} l_{j t}-\int x_{j t}(i) p_{j t}(i) d i\right\}
$$

The return to an innovator for customizing intermediate $i$ for a given firm is:

$$
\pi_{j t}=x_{j t}(i)(\chi-1) q_{j t}
$$

where $x_{j t}(i)$ is the demand by the firm for the intermediate at the given price $p_{j t}(i)$. Entrepreneurs may enter any industry so, in any equilibrium in which there is production in all industries, it must be that the profits from entrepreneurship in any industry are equal: $\Pi_{j t}^{E}=\Pi_{t}^{E} \forall j$. In equilibrium agents are indifferent between research, entrepreneurship and work, so $\Pi_{t}^{E}=\Pi_{t}^{R}=1$, where $\Pi_{t}^{R}$ is the return to research. Entrepreneurs may enter any industry of their choice. Let $M_{j t}$ be the mass of firms in each industry, so that the total mass of firms $M_{t} \equiv \sum_{j} M_{j t}$

\footnotetext{
${ }^{5}$ The assumption that $x_{j t}(i)$ requires good $j$ for its production has several interpretations: (1) literally in terms of intermediate use of good $j$, in which case the assumption is consistent with the fact that inputouput tables are generally sparse away from the diagonal; (2) in terms of "prototype" goods that are not for sale but which must be produced to learn the optimal configuration of product features or that are simply "tests" or "failed attempts" at production; or (3) in terms of productivity, or "output foregone," so that R\&D literally increases the "yield" of productive activity, defined as $y_{j t}-\int\left[\mu_{j t}(i)+\chi\left(1-\mu_{j t}(i)\right)\right] x_{j t}(i) d i$ where $\mu_{j t}(i)=1$ if research on $i$ was successful and $\mu_{j t}(i)=0$ otherwise.
} 


\section{Research}

Young agents decide whether in their old age they will become entrepreneurs, researchers, or continue as workers. If they become entrepreneurs, they choose an industry to enter and forego their ability to supply labor to the market when old. If they become researchers, they may be matched with an entrepreneur for whom to perform research, and also forego their ability to supply labor to the market when old. Entrepreneurs and researchers are matched pair-wise according to the function

$$
M_{t}=\min \left\{N_{t}^{E}, N_{t}^{R}\right\}
$$

where $M_{t}$ is the number of matches, $N_{t}^{E}$ is the number of entrepreneurs and $N_{t}^{R}$ is the number of researchers. Since the population of old agents is 1, and only old agents may become entrepreneurs or researchers, we require $N_{t}^{R}+N_{t}^{E} \leq 1$..

Researchers are able to customize intermediates for the entrepreneur they are matched with. Consider a firm (match) active in period $t$. Customized intermediates are used at the frontier productivity $A_{j t}^{*}$, whereas other intermediates are used at the previous period's productivity $A_{j, t-1}(i)$.

At a certain cost, the researcher uncovers how to customize for the firm a random subset of intermediates $[0,1]$ of measure $\mu_{j t}$. For a given choice of $\mu_{j t}$, the research cost equals $\tilde{n}_{j}\left(\mu_{j t}\right) / a_{j, t-1}$ units of labor. The cost is incurred at the end of youth, and the research output (the new knowledge) appears at the beginning of the researcher's old age. As in Jovanovic and Nyarko (1996), the research cost is increasing in the gap between the current state of technology and the frontier. ${ }^{6}$

Industries vary in terms of $\tilde{n}_{j}(\cdot)$, the R\&D cost function. Specifically, we assume that there is an industry-specific parameter $\kappa_{j}>0$ that scales the cost of research, so $\tilde{n}_{j}\left(\mu_{j t}\right)=$ $\kappa_{j} n\left(\mu_{j t}\right)$. The function $n(\cdot)$ satisfies the following assumptions: $n(0)=0, \lim _{\mu \rightarrow 1} n(\mu)=$ $\infty, n^{\prime}(\mu)>0$ and $n^{\prime \prime}(\mu)>0$. All these properties are inherited by $\tilde{n}_{j}(\cdot) .^{7}$

Parameter $\kappa_{j}$ is central to industry variation in productivity dynamics. Industries with lower $\kappa_{j}$ need to devote fewer resources to $\mathrm{R} \& \mathrm{D}$ to achieve the same rate of innovation success $\mu_{j t}$. This is consistent with Ngai and Samaniego (2011), who consider a variety of possible determinants of $R \& D$ intensity in a general equilibrium model and find that differences in

\footnotetext{
${ }^{6}$ In AHM, the cost of R\&D is increasing in the level of the frontier, rather than the gap from the frontier. We prefer our specification as it implies that an agent's pre-existing knowledge lowers the cost to acquiring new knowledge. Several papers such as Caballero and Jaffe (1993) and Ngai and Samaniego (2011) provide evidence that prior knowledge eases the acquisition of new knowledge.

${ }^{7}$ In AHM, the function $\tilde{n}(\cdot)$ is quadratic, which does not restrict $\mu$ to lie in the interval $[0,1]$.

Note that $\kappa_{j}$ is a parameter, whereas $a_{j t}$ is determined endogenously, except when $t=0$.
} 
the productivity "yield" of R\&D spending are the main factor behind industry differences in R\&D intensity - see also the survey of Cohen and Levin (1989). In equilibrium, the relationship between $\kappa_{j}$ and optimal research intensity will depend on the optimal choice of $\mu_{j t}$ in each industry. Later we show that if research intensity and productivity growth are positively related (as indicated by empirical evidence), then $\kappa_{j}$ is negatively related to R\&D intensity.

A researcher chooses $\mu_{j t}$ to maximize the discounted profits from research minus the up-front cost of R\&D: ${ }^{8}$

$$
\begin{aligned}
\Pi_{j t}^{R}= & \frac{1}{\rho} \max _{\mu_{j t}}\left\{\rho \pi_{j t} \mu_{j t}-\tilde{n}_{j}\left(\mu_{j t}\right) / a_{j, t-1}\right\} \\
& \text { s.t. } \tilde{n}_{j}\left(\mu_{j t}\right) / a_{j, t-1} \leq F S_{t} .
\end{aligned}
$$

$\Pi_{j t}^{R}$ is the discounted profit from research as seen from the date at which profits are realized: it will be convenient to define $\Pi_{j t}^{R}$ in these terms, so that it can be easily compared with $\Pi_{j t}^{E}$. Variable $S_{t}$ is the researcher's own funds devoted to R\&D at the end of their youth, which cannot exceed their wages from the first period. Since the wage is equal to one, and since agents are indifferent about the date of consumption, $R \& D$ spending is bounded above by $F S_{t}$.

Definition 1 Parameter $F$ is the level of financial development, representing the quality of institutions that relax financing constraints (for example, via transparency, disclosure or property rights).

We assume that $F$ is fixed for a given country, reflecting the view that financial development is a function of "deep" institutions such as property rights and contract enforcement, which do not change often (see Acemoglu and Johnson (2005)). $F \geq 1$ is interpreted as a borrowing limit, as in Evans and Jovanovic (1989) and AHM. Allowing $F<1$ implies that an underdeveloped financial system may limit the ability to invest as well as the ability to borrow. The limit $F$ only applies to R\&D investments, which take a period to bear fruit. That R\&D investments suffer from particular financing difficulties is discussed in Carlin and Mayer (2003) and Hall (2005). ${ }^{9}$ AHM argue this may occur because the output of R\&D may

\footnotetext{
${ }^{8}$ More generally, they maximize $\rho \pi_{j t} \mu_{j t}-S_{t}-\rho(1+r)(F-1) S_{t}$ subject to the financing constraint and $\tilde{n}_{j}\left(\mu_{j t}\right) / a_{j, t-1}=S_{t}+(F-1) S_{t}$, where $(1+r)$ is the interest factor on borrowed funds. However, since utility is linear and agents can borrow/lend as much as they like for consumption purposes, $(1+r)=\rho^{-1}$ and we have the simpler problem (10).

${ }^{9}$ In the technical appendix we show that R\&D intensity is positively linked to measures of the inability to raise external funds at the firm level: asymmetric information (measured as the dispersion of analyst long-term forecasts) and asset intangibility (one minus the share of fixed assets).
} 
be difficult to verify or to characterize in contracts, and Ilyina and Samaniego (forthcoming) find that the finance-induced growth of $\mathrm{R} \& \mathrm{D}$ intensive industries is related to intellectual property rights enforcement. While financing constraints may affect production as well, Ilyina and Samaniego (forthcoming) find that financing constraints on R\&D are particularly relevant for understanding industry growth differences, so we abstract from financial constraints on non-R\&D activities.

\section{Productivity dynamics}

Under these assumptions, productivity dynamics at the firm level can be described as follows. For each industry $j$, there is a world technology frontier $A_{j t}^{*}$ for the efficiency of customized intermediates. Each period the frontier expands by a factor $g_{j}$, which firms take as given.

Suppose that research succeeds over a random subset of intermediates of measure $\mu_{j t}$. Then, $A_{j t}(i)=A_{j t}^{*}$ with probability $\mu_{j t}$, and $A_{j t}(i)=A_{j, t-1}(i)$ with probability $1-\mu_{j t}$. Assuming that the chance of a successful innovation is uncorrelated with $i$, firm productivity evolves according to: ${ }^{10}$

$$
A_{j t}=A_{j t}^{*} \mu_{j t}+A_{j, t-1}\left(1-\mu_{j t}\right)
$$

It will be useful to specify (11) in terms of productivity gaps $a_{j t}$. Recalling that $a_{j t} \equiv A_{j t} / A_{j t}^{*}$, (11) can be rewritten:

$$
a_{j t}=\mu_{j t}+\frac{\left(1-\mu_{j t}\right)}{g_{j}} a_{j, t-1}
$$

\section{E Technological frontier}

Industries with rapid technological progress also tend to be R\&D intensive - as found by Terleckyj (1980) and Ngai and Samaniego (2011) among others. We generate this regularity in the model by endogenizing movements in the technological frontier, via spillovers from research. Alternatively, we could simply impose this as an empirically-motivated assumption.

To endogenize $g_{j}$, we assume the existence of a "benchmark economy", where financial development is at some level $F^{*}$ that is sufficiently high that financing constraints do not bind in any industry. As a result, R\&D investment is always at the optimal level. We assume that the benchmark economy drives the path of technical progress in all other countries: $g_{j}$ is determined in the benchmark economy. This is similar to "North-South" models of tech-

\footnotetext{
${ }^{10}$ In principle, the entrepreneur can keep her "initial" productivity: however, as is typical of quality ladder models, she will be at least as well off adopting the new technology.
} 
nology adoption where technological progress originates in a large and relatively undistorted economy, whereas other smaller economies are adopters (see Acemoglu and Zilibotti (2001)).

If financing constraints do not bind, research activity and the industry's position relative to the technological frontier each converge to limiting values: there exist numbers $a_{j}^{*}$ and $\mu_{j}^{*}$ such that $a_{j t} \rightarrow a_{j}^{*}, \mu_{j t} \rightarrow \mu_{j}^{*}$. We assume that industries in the benchmark economy have converged to these values, so $\mu_{j t}=\mu_{j}^{*}$ and $a_{j t}=a_{j}^{*} \forall j, t$. Productivity gaps $a_{j t}$ in economies where financing constraints do bind may or may not converge to $a_{j}^{*}$ equilibrium.

The expansion of the technological frontier in each industry $j$ is driven by spillovers from research in the benchmark economy, so that:

$$
g_{j}=\sigma \mu_{j}^{*}+1, \sigma>0
$$

where $\sigma$ is a spillover coefficient. Thus, R\&D is carried out by firms in order to produce output using the frontier level of knowledge, but in the benchmark economy research also has the effect of pushing the frontier forward, through spillovers.

We define the following "industry characteristics", based on optimal behavior in the benchmark economy.

Definition 2 The $\boldsymbol{R} \mathscr{G} \boldsymbol{D}$ intensity of industry $j$ is the RED share of expenditures in industry $j$ in the benchmark economy: $R N D_{j} \equiv \frac{\kappa_{j} n\left(\mu_{j}^{*}\right) / a_{j}^{*}}{l_{j t}+\int x_{j t}(i) p_{j t}(i) d i} \cdot{ }^{11}$

Definition 3 The need for external funds of industry $j$ is the amount of external funds as a share of expenditures of industry $j$ in the benchmark economy: $E F D_{j} \equiv \frac{\kappa_{j} n\left(\mu_{j}^{*}\right) / a_{j}^{*}-S}{l_{j t}+\int x_{j t}(i) p_{j t}(i) d i}$, where $S$ is the amount of internal funds. ${ }^{12}$

Lemma 1 There exists $\kappa^{*}$ such that $R N D_{j}, \mu_{j}^{*}$ and $g_{j}^{*}$ are positively related across industries for $\kappa_{j} \in\left[\kappa^{*}, \infty\right)$. There exists $\kappa^{* *}>\kappa^{*}$ such that $R N D_{j}$ is zero for $\kappa_{j} \in\left[\kappa^{* *}, \infty\right)$.

Observe that R\&D intensity and the need for external funds are positively related, as in the data. The data also indicate that research spending and productivity growth are positively related, which occurs for $\kappa_{j} \in\left[\kappa^{*}, \infty\right)$. We assume for the remainder of the paper that $\left\{\kappa_{j}\right\}_{j}$ all fall in this range.

${ }^{11}$ There are several ways to specify R\&D intensity. With $\mathrm{R} \& \mathrm{D} \operatorname{costs} \kappa_{j} n\left(\mu_{j}^{*}\right) / a_{j}^{*}$, the firm (the entrepreneur-researcher pair) earn $p y-l_{j t}-\kappa_{j} n\left(\mu_{j}^{*}\right) / a_{j}^{*}$. This is split so the entrepreneur gets $p y-l_{j t}-$ $\int x_{j t}(i) p_{j t}(i) d i$ and the researcher gets $\int x_{j t}(i) p_{j t}(i) d i-\kappa_{j} n\left(\mu_{j}^{*}\right) / a_{j}^{*}$. If we view both agents as equity holders, then their compensation is not an expense, so "expenses" equals $l_{j t}+\kappa_{j} n\left(\mu_{j}^{*}\right) / a_{j}^{*}$.

Alternatively, if we view the researcher's compensation as an expense (which is common accounting practice), then total costs equal $l_{j t}+\int x_{j t}(i) p_{j t}(i) d i$. Finally, R\&D intensity could be instead defined as a share of sales. All these measures are positively related, so results are the similar regardless of the definition.

${ }^{12}$ In equilibrium, $S=\min \left\{\kappa_{j} n\left(\mu_{j}^{*}\right) / a_{j}^{*}, 1\right\}$. 


\section{Model Equilibrium}

In any model of occupational choice, the expected marginal benefit of all activities must be equal in equilibrium. In a multisector model with $R \& D$-driven productivity change, this presents a problem to the modeler. To the extent that the costs and benefits of R\&D change over time, and that these changes occur at different rates in different industries, changes in product prices may not just reflect productivity change, but also the changing cost of R\&D. We refer to this phenomenon research pass-through. While research pass-through is a phenomenon of interest, its presence greatly complicates the model and, as argued in the technical appendix, it is unlikely to be quantitatively significant. In the remainder of the paper we focus on equilibria in which $N_{t}^{R} \geq N_{t}^{E}$, which rules out research pass-through. ${ }^{13}$ We derive sufficient conditions for the existence of such equilibria, and discuss equilibria with $N_{t}^{R}<N_{t}^{E}$ in the technical appendix.

Definition 4 An equilibrium with $N_{t}^{R} \geq N_{t}^{E}$ is a set of sequences of values for prices $q_{j t}, p_{j t}$, resource allocation $l_{j t}, x_{j t}$, investments $b_{t}$ and $S_{t}$, and consumption decisions $c_{j t}$, occupational choice decision $\theta$, occupational composition $N_{t}^{R}, N_{t}^{E}$, a number of firms in each industry $M_{j t}$ and RED decisions $\mu_{j t}$, productivity gaps $a_{j t}$ and growth rates $g_{j}$ such that, for all $j$ and $t$, and for given initial conditions $a_{j 0}$ :

1. The markets for all goods $j$ and bonds $b_{t}$ clear and resource constraints are met given $p_{j t}, q_{j t}{ }^{14}$

2. Occupational choice decisions are optimal: $\theta$ solves (4) subject to (2) and (3).

3. Consumption and labor input decisions are optimal given $q_{j t}, p_{j t}$ : $c_{j t}$ solves (4) subject to $(2)$ and (3).

4. $N_{t}^{R}, N_{t}^{E}$ and $M_{j t}$ satisfy $\sum_{j} M_{j t}=N_{t}^{E}, \Pi_{t}^{E}=\Pi_{t}^{R}=1$ and $N_{t}^{R}+N_{t}^{E} \leq 1$.

5. Input usage in RED and in production is optimal $-x_{j t}, \mu_{j t}$ and $l_{j t}$ solve (7) and (10).

6. The sequence $\left\{a_{j t}\right\}_{t=0}^{\infty}$ satisfies (12).

7. $g_{j}$ satisfies condition (13).

\footnotetext{
${ }^{13}$ In essence, researchers do not know ex-ante the industry in which they will end up being employed, and there may be "excess supply" into R\&D so that in expectation the return to R\&D is constant over time. Thus, for example, a chemistry Ph.D might end up working in Pharmaceuticals (ISIC 352), Food (311), Leather (323) or Finance (651), depending on the vicissitudes of the market for research labor.

${ }^{14}$ Feasibility and market clearing conditions are reported in the Appendix.
} 
Proposition 1 (Existence) Given $F$ and $\left\{a_{j 0}\right\}$, there is a number $\bar{\alpha}<1-\alpha_{x}$ such that if $\alpha_{l}>\bar{\alpha}$ then there exists a unique equilibrium in which $N_{t}^{R} \geq N_{t}^{E}$. Along the equilibrium path, the rate of aggregate growth converges to a constant.

Remark 5 A sufficient condition for equilibrium existence is that the entrepreneur's share of income $1-\alpha_{l}-\alpha_{x}$ is not too large, which ensures that at least as many old agents wish to be researchers as entrepreneurs.

\section{A Industry growth}

We consider a less-financially developed economy, in which initial productivity gaps satisfy $a_{j 0} \leq a_{j}^{*}$ in all industries $j$. We begin by studying patterns of growth and productivity change at the industry level, and then use them to derive aggregate outcomes.

First, how do industry productivity dynamics translate into industry growth? The total value of final goods produced in any industry is $q_{j t} \bar{c}_{j t}$ - where $\bar{c}_{j t}$ represents consumption at date $t$ by both the young and the old and $q_{j, t}$ is its price. Define $G_{j t}=\frac{q_{j, t+1} \bar{c}_{j, t+1}}{q_{j t} \bar{c}_{j t}}$ as the growth factor of industry $j$. The expression $G_{j t} / G_{j^{\prime}, t}$ then denotes the growth of industry $j$ relative to industry $j^{\prime}$.

As in Ngai and Pissarides (2007), CES preferences imply that industry growth satisfies: $\frac{G_{j t}}{G_{j^{\prime}, t}}=\left(\frac{q_{j, t+1} / q_{j t}}{q_{j^{\prime}, t+1} / q_{j^{\prime}, t}}\right)^{1-\varepsilon}$. Hence, to understand the implications of the productivity dynamics for industry growth, we need to derive the relationship between relative prices and relative productivity values. In the model, a decrease in the relative price of good $i$ compared to good $j$ implies a commensurate increase in the productivity of $i$-production compared to j-production. As a result:

Proposition 2 (Structural Change) In equilibrium, differences in productivity growth rates across industries can be decomposed into differences in the growth rates of their technological frontiers $g_{j}$ and differences in the rates of change of $a_{j, t}$ - the productivity growth rates of industries relative to their technological frontiers:

$$
\frac{G_{j t}}{G_{j^{\prime} t}}=\left(\frac{a_{j, t+1}}{a_{j^{\prime}, t+1}} / \frac{a_{j t}}{a_{j^{\prime}, t}}\right)^{\varepsilon-1} \times\left(\frac{g_{j}}{g_{j^{\prime}}}\right)^{\varepsilon-1} .
$$

The ratio $\frac{a_{j, t+1}}{a_{j t}}$ represents the rate of convergence of productivity in industry $j$ to its technological frontier. Hence, industries grow or shrink relative to each other depending on the value of the elasticity of substitution parameter $\varepsilon$, on relative rates of expansion of their technological frontiers, and on relative rates of convergence of different industries to their respective technological frontiers. Since technological frontiers are shared in all countries, all country differences in industry growth must be due to differences in convergence rates. 


\section{B Aggregate growth}

Before discussing patterns of structural change, we characterize aggregate growth in a less financially-developed economy. Several properties are shared with the one-sector AHM model: however, these properties occur for different reasons in a multisector framework. In the Appendix, we show that productivity in an individual industry $j$ may converge to productivity in the benchmark economy, but only provided financial development $F$ exceeds an industry-specific threshold $\bar{F}_{j}$

There is another threshold $\underline{F}_{j}$ such that, if $F<\underline{F}_{j}$, industry productivity falls further and further behind the frontier so that $\frac{a_{j, t}}{a_{j, t-1}} \rightarrow 0$. If $F \in\left(\underline{F}_{j}, \bar{F}_{j}\right)$, then $\frac{a_{j, t}}{a_{j, t-1}}$ converges to a positive constant that is decreasing in $F$, so industry productivity lags permanently behind the industry in the benchmark economy, but it does not fall further and further behind over time. The thresholds $\left\{\underline{F}_{j}, \bar{F}_{j}\right\}_{j=1}^{J}$ depend on parameters, but not on initial conditions $\left\{a_{j, 0}\right\}_{j=1}^{J}$. In a multi-industry context, the impact of financing constraints $F$ on aggregate growth depends on these industry dynamics, but also on how the structure of the economy varies in response to these dynamics.

Let $Y_{t}$ equal aggregate production. - so that $Y_{t}=\sum_{j} q_{j t} \bar{c}_{j t} .{ }^{15}$ Let $G_{t}$ equal the growth factor of GDP, and let $Y_{t}^{*}$ and $G_{t}^{*}$ respectively be the level and growth factor of GDP in the benchmark economy. For given initial conditions, financial development may affect $G_{t}$ in transition so long as any single industry is financially constrained. However, in the long run this effect may wear off. To characterize the long run effect of $F$ we classify limiting behavior as follows:

Definition 6 In a development trap, $\lim _{t \rightarrow \infty} \frac{G_{t}}{G_{t}^{*}}=1$ and $0<\lim _{t \rightarrow \infty} \frac{Y_{t}}{Y_{t}^{*}}<1$. The economy converges to the benchmark economy in terms of growth rates, but not GDP levels.

Definition 7 In a development sink, $\lim _{t \rightarrow \infty} \frac{G_{t}}{G_{t}^{*}}<1$. The economy falls steadily behind the benchmark economy, converging neither in levels nor in growth rates.

Proposition 3 (Convergence I) In equilibrium there are threshold levels of financial development $\bar{F}$ and $\underline{F}$ that are independent from initial conditions $\left\{a_{j 0}\right\}_{j=1}^{J}$, such that

i) output converges to output in the benchmark economy for $F \geq \bar{F}$,

ii) the model economy falls into a development trap for $F \in(\underline{F}, \bar{F})$, where $\lim _{t \rightarrow \infty} \frac{Y_{t}}{Y_{t}^{*}}$ is decreasing in F;

iii) the model economy falls into a development sink if $F \leq \underline{F}$.

Define $j^{\text {high }}$ as the most R\&D-intensive industry, and $j^{\text {low }}$ as the least.

\footnotetext{
${ }^{15}$ Current national income accounting procedures do not consider R\&D as part of GDP. This approach will simplify our discussion of the aggregate impact of financing constraints.
} 
Proposition 4 (Convergence II) If $\varepsilon>1$, the thresholds are determined by the most REDD-intensive industry: $\bar{F}=\bar{F}_{j^{\text {high }}}$ and $\underline{F}=\underline{F}_{j^{\text {high }}}$. If $\varepsilon<1, \bar{F}=\bar{F}_{j^{\text {low }}}$ and $\underline{F}=\underline{F}_{j^{\text {low }}}$.

While statements (i)-(iii) in Proposition 3 are similar to the "convergence club" results of AHM, Proposition 4 shows that the underlying mechanisms are more complicated. In a single-industry context, financial development affects growth by reducing the gap between productivity growth in the developing economy and the rate of expansion of the technological frontier. In our multi-industry context, the same mechanism operates at the industry level but, in addition, aggregate growth rates are affected by equilibrium patterns of structural change, as industry shares of output evolve over time. In particular, if $\varepsilon>1$, resources are shifted away from industries with relatively slower productivity growth, so that an economy falls into a development trap if and only if the industry with the fastest rate of expansion of its technological frontier does not converge to the level of productivity in the benchmark economy. If $\varepsilon>1$, an economy falls into a development sink if and only if the industry with the fastest rate of expansion of its technological frontier experiences such severe financial constraints that it is unable even to keep pace with the growth rate of the productivity frontier. ${ }^{16}$

As discussed in the technical appendix, the model economy can be generalized to have several industries in the limit, each of which will be among the most R\&D intensive if $\varepsilon>1$. The implication is that a multi-sector generalization of AHM is in fact more sensitive to financing constraints than a one-sector version. In a calibrated or estimated one-sector model, dynamics will be driven by average $R \& D$ intensity, whereas in a multi-sector context what determines convergence in the long run are the most R\&D-intensive and externalfinance dependent industries - not the measured country average in transition.

\section{Industry growth and structural change}

\section{A Patterns of structural change}

Next we explore the implications of industry productivity dynamics for patterns of structural change. Proposition 2 implies that structural change is determined by industry differences in frontier productivity growth $g_{j}$ and by industry differences in rates of productivity convergence to that frontier. Define $\gamma_{j} \equiv a_{j, t+1} / a_{j t}$ at a given date $t$, and for given initial conditions $\left\{a_{j, 0}\right\}_{j=1}^{J}$. Recall that the industry productivity growth factor equals $\gamma_{j} g_{j}$ and that, if $\varepsilon>1$, relative productivity growth maps monotonically into relative industry growth.

\footnotetext{
${ }^{16}$ In the model, the assumption that $\varepsilon>1$ is required for productivity growth differences to map positively into industry growth differences. In Section $V$ we report evidence consistent with this assumption.
} 
Consider a financially constrained industry. It is straightforward to show that financial development accelerates productivity convergence $\left(\frac{\partial \gamma_{j}}{\partial F} \geq 0 \forall j\right)$. In addition:

Proposition 5 ( $R E B D$ costs and industry growth) In the model, financial development leads to a greater acceleration in convergence rates in industries with a low REDD cost parameter $\left(\frac{\partial^{2} \gamma_{j}}{\partial F \partial \kappa_{j}} \leq 0\right)$.

There are two effects driving the result in Proposition 5, reflected in two separate terms in the expression for $\frac{\partial^{2} \gamma_{j}}{\partial F \partial \kappa_{j}}$.

- The R\&D cost function itself depends on $\kappa_{j}$. For lower values of $\kappa_{j}$, a given decrease in R\&D spending yields a larger decrease in $\mu_{j t}$, and hence a greater deceleration in convergence rates. We call this the need effect.

- To the extent that firms do not perform R\&D, their position relative to the productivity frontier deteriorates at rate $g_{j}$. Since $\frac{\partial g_{j}}{\partial \kappa_{j}}<0$ in the empirically relevant range, this particularly affects $\mathrm{R} \& \mathrm{D}$ intensive industries. We call this the convergence effect.

This suggests that RZ result is due to the fact that the need for external finance is correlated with RED intensity. If not, the convergence effect would not be present, because high-need industries would not fall behind the frontier more rapidly under financing constraints. The need effect would not be present either, since it would not be that an extra dollar spent in high-need industries disproportionately accelerates productivity growth.

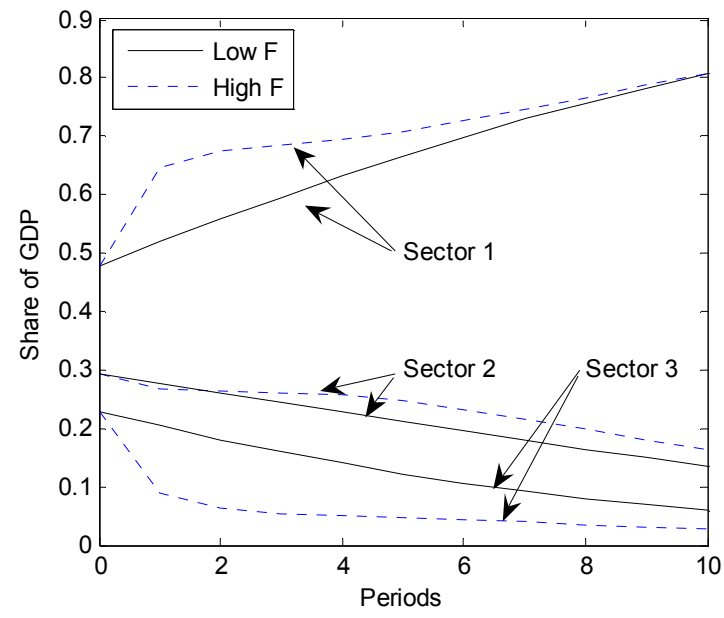

Figure 1 - Structural change in a model economy with three industries. The dotted line represents a financially unconstrained economy, and the solid line represents a financially constrained economy. Sector 1 has the lowest value of $\kappa_{j}$ and Sector 3 has the highest. 
Suppose that $\varepsilon>1$. Figure 1 illustrates the patterns of structural change implied by Proposition 5. Consider two economies with the same vector of initial conditions $\left\{a_{j 0}\right\}_{j}$ for each industry, but different levels of financial development - one is financially constrained and the other one is not. Productivity growth in a financially constrained economy is lower than in an unconstrained economy, particularly in industries with the most rapid expansion of the technological frontier. Consequently, industry differences in productivity growth rates are smaller than in a financially constrained economy. Both financially unconstrained and financially constrained economies converge to the same optimal industry structure in the long run (unless the latter falls into a development sink). However, since structural change is driven by productivity growth differences, convergence to this long run optimal structure will be more rapid in the case of a more financially developed economy.

This result underlines a channel whereby financial development leads to economic growth that can only be identified in a multi-industry model. A loosening of financing constraints allows not only improvements in R\&D-driven productivity but also, in a multi-industry context, this leads to a more rapid reallocation of resources towards the sectors that most benefit from these improvements - provided $\varepsilon>1$.

Notice the dependence on the value of $\varepsilon$, which is a demand side parameter not commonly thought of as being relevant for the finance-growth link. If $\varepsilon<1$, then disproportionate productivity improvements in industry $i$ lead to a more rapid reallocation of resources away from the production of good $i$. This underlines the importance of general equilibrium analysis for deriving predicted empirical specifications and for interpreting empirical results in a multi-industry environment.

\section{B Decomposing Industry Growth}

The prediction in Proposition 5 could be hard to corroborate empirically due to the fact that countries may differ significantly in terms of initial conditions. However, the model turns out to suggest an alternative methodology for detecting the conditional compression of industry productivity growth rates caused by financial development: estimating a differencesin-differences regression specification similar to that in RZ.

According to Equation (14), relative industry growth rates can be decomposed into a part that is due to the movement of the technological frontier, and a part due to relative industry convergence rates. Let $G_{j k}$ be the growth factor of value added for industry $j$ in country $k$, and let $a_{j k}$ be the initial productivity gap. Also, let $\gamma_{j k}\left(F, a_{j k}, \kappa_{j}\right)$ be the growth rate of $a_{j k}$, referred to earlier as the rate of industry productivity convergence. Fixing an 
arbitrary industry $j^{\prime}$ as a benchmark, (14) can be written:

$$
\log G_{j k}=\beta_{j}+\beta_{k}+(\varepsilon-1) \log \gamma_{j k}\left(F, a_{j k}, \kappa_{j}\right)
$$

where $\beta_{j}=(\varepsilon-1) \log g_{j}$ and $\beta_{k}=\log G_{j^{\prime}, k}-(\varepsilon-1) \log \gamma_{j^{\prime}, k}-(\varepsilon-1) \log g_{j^{\prime}}$.

Decomposing $\gamma_{j k}$ using a second-order Taylor approximation, in the Appendix we show that equation (15) can be written:

$$
\begin{aligned}
\log G_{j k}= & \tilde{\beta}_{j}+\tilde{\beta}_{k}+\beta_{F, R N D} F_{k} \times R N D_{j}+\beta_{F, s} F_{k} \times a_{j k} \\
& +\beta_{R N D, a} R N D_{j} \times a_{j k}+\beta_{s} a_{j k}+\beta_{s^{2}} a_{j k}^{2}+\epsilon_{j k} .
\end{aligned}
$$

In equation (16), $R N D_{j}$ is research intensity in industry $j$, which is negatively related to $\kappa_{j}$. $F_{k}$ is a measure of financial development.

The remaining coefficients relate to cross-derivatives among country and industry variables, or to derivatives with respect to initial conditions. Assuming that $\varepsilon>1$, so that the sign of derivatives of $\gamma_{j k}(\cdot)$ is preserved when deriving the impact on industry growth, we have that:

- The coefficient $\beta_{F, R N D}$ indicates whether financial development affects industries differently, depending on their R\&D intensity. Based on Proposition 5, we expect that $\beta_{F, R N D}>0$, as $\frac{\partial^{2} \gamma}{\partial F \partial \kappa}<0$ and since $\kappa_{j}$ is inversely related to $R N D_{j}$.

- $\beta_{a}$ and $\beta_{a^{2}}$ account for differences in initial conditions. If industries with larger productivity gaps tend tend to grow faster then we expect that $\beta_{a}<0$ and possibly $\beta_{a^{2}}>0$ if greater distance from the frontier implies disproportionately rapid convergence.

- The coefficient $\beta_{R N D, a}$ indicates whether being closer to the technological frontier affects industries differently depending on their R\&D intensity. $\beta_{R N D, a}<0$ would indicate that, for a given initial condition $a_{j k}$, research-intensive industries converge faster.

- The coefficient $\beta_{F, a}$ indicates whether financial development affects industries differently depending on their position relative to the technological frontier. $\beta_{F, a}<0$ would indicate that financial development makes convergence more rapid particularly for industries with wider productivity gaps. ${ }^{17}$

\footnotetext{
${ }^{17}$ The model has no prediction for the sign of $\beta_{R N D, a}$ nor $\beta_{F, a}$. In the technical appendix, we estimate (16) and find that these interaction terms are generally not statistically significant, but that their inclusion does not affect the sign nor significance of $\beta_{F, R N D}$.
} 
It is worth noting that the regression specification in RZ is closely related to equation (16). Their specification is:

$$
\log G_{j}^{k}=\beta_{j}+\beta_{k}+\beta_{F, E F D} F_{k} \times E F D_{j}+\beta_{s} s_{j k}+\epsilon_{j k}
$$

where $E F D_{j}$ is their measure of external finance dependence and $s_{j k}$ is the share of manufacturing GDP of industry $j$. Equation (17) is a restricted form of equation (16), replacing the interaction term $\beta_{F, R N D} F_{k} \times R N D_{j}$ with $\beta_{F, E F D} F_{k} \times E F D_{j}$, assuming that the second order terms other than $\beta_{F, R N D}$ equal zero, and assuming that $s_{j k}$ is an adequate proxy for $a_{j k}$ - something that we show in the Appendix to be reasonable under certain conditions. The specification in Fisman and Love (2007) is also similar to (17), replacing the interaction term $\beta_{F, E F D} F_{k} \times E F D_{j}$ with $\beta_{F, G R} F_{k} \times G R_{j}$, where $G R_{j}$ is a measure of benchmark industry growth. ${ }^{18}$ The specification in Ilyina and Samaniego (forthcoming) is also similar except that research intensity, rather than finance dependence, is interacted with financial development. The fact that previous research finds positive and significant coefficients for the interaction term of each of these variables with financial development validates the model structure (within which all three variables $R N D_{j}, E F D_{j}$ and $G R_{j}$ are positively related) and supports the prediction of Proposition 5.

Notice again the dependence of these results on the value of $\varepsilon$. Equation (15) shows that statements about productivity convergence rates $\gamma_{j k}$ translate monotonically into statements about industry growth only provided $\varepsilon>1$. Otherwise, the prediction of the model for the sign of the interaction term of financial development with either of $R N D_{j}, E F D_{j}$ and $G R_{j}$ would be reversed. There are two implications. First, it is distinctly possible for finance to encourage growth by allocating greater resources towards productivity-enhancing R\&D, yet for the sign of the interaction coefficient in the celebrated RZ regression to be negative. Thus, the logic underlying such industry regressions carries an implicit assumption on the value of $\varepsilon$. Second, for the model to be consistent with the results in RZ, Fisman and Love (2007) and Ilyina and Samaniego (forthcoming), it must be that $\varepsilon>1$. Again, the reason is that productivity change in industry $i$ reduces the price of good $i$ in equilibrium, and whether or not this leads to an increase or a decrease in the share of expenditure on good $i$ depends on the elasticity of substitution across goods. In fact, the value of $\varepsilon$ across the broad sectors Agriculture, Manufacturing, and Services is thought to be less than one (see Ngai and Pissarides (2007)) but we will revisit the issue below.

\footnotetext{
${ }^{18}$ Fisman and Love (2007) interpret the benchmark industry growth rate as a short term statistic: without detracting from their analysis, Ilyina and Samaniego (forthcoming) find that the industry correlation between this measure for the 1980s and 1990s is 84 percent, suggesting that the measure is also associated with longer term patterns of structural change.
} 
Fisman and Love (2007) interpret their measure of industry growth as representing "growth opportunities". In the model, when $\varepsilon>1$, these "opportunities" take the form of changes in demand driven by different rates of technical progress in different industries. In general equilibrium, these opportunities are both created and exploited by means of R\&D, and fuelled by external finance - as firms perform R\&D to increase productivity, and as productivity change induces price declines that lead to increases in product demand.

To sum up, the analysis shows that interaction terms in popular differences-in-differences industry growth regressions may be interpreted in terms of the impact of financial development on the pace of structural change. Conditional on industry shares, financial development particularly improves growth in R\&D-intensive industries, because these are industries where a given amount of $\mathrm{R} \& \mathrm{D}$ has a greater impact on convergence, where productivity growth is most rapid, and where the need for external finance is highest.

\section{Quantitative Results}

We now calibrate the model economy and use information on country R\&D expenditures to infer the level of financing constraints implied by the model. Industry parameters are calibrated to ensure that the costs and benefits of $R \& D$ are of empirically relevant magnitudes. We verify whether financing constraints identified in this way are related to independent measures of financial development, and also whether industry growth rates in the calibrated model display a measurable interaction in a differences-in-differences specification (equation (17)). Unless otherwise indicated, data cover the period 1990-1999, including the same sample of 41 countries as Rajan and Zingales (1998), Fisman and Love (2007) and Ilyina and Samaniego (forthcoming).

\section{A Country Data}

Research expenditures at the country level are drawn from the World Bank's World Development Indicators 2002. This source reports R\&D spending as a share of GDP. We will use this information as an aid to calibrating the model. Since we will be calibrating to manufacturing data, we require a measure of $R \& D$ intensity in the manufacturing sector. We obtain this by assuming that all $R \& D$ spending is performed in manufacturing, and adjust the numbers using the manufacturing share of GDP in each country. Although manufacturing is indeed responsible for the majority of $R \& D$, this overstates $R \& D$ intensity in the manufacturing sector somewhat. Correspondingly, this has the effect of understating somewhat the impact of financing constraints, since we will calibrate financing constraints 
to match the R\&D spending numbers.

The industry share of manufacturing i.e. the share $s_{j k}$ of industry $j$ in the manufacturing value added of country $k$, is drawn from the Industrial Statistics Database (INDSTAT3) provided by the United Nations Industrial Development Organization (UNIDO). We show in the Appendix how to derive measures of $a_{j k}$ in the model based on data shares $s_{j k}$ : essentially, given a benchmark industry $j^{\prime}$, relative values of $s_{j k} / s_{j^{\prime} k}$ in any two countries are a function of $a_{j k} / a_{j^{\prime} k}$ and of $\varepsilon$.

\section{B Industry data}

Industry measures are constructed for the 28 manufacturing industries in INDSTAT3. We seek measures of financing and research activity that are not themselves affected by financing constraints. We use data on publicly traded US firms, following the argument that (in normal times) these firms have access to highly liquid capital markets so that the median firm in a given industry in Compustat is not constrained.

We measure the observed need for external finance $E F D_{j}$ using the share of expenditures that is not financed by cash flow from operations, following Rajan and Zingales (1998), and as reported in Ilyina and Samaniego (forthcoming) for the 1990s.

Research intensity $\left(R N D_{j}\right)$ is defined as R\&D expenditures (DATA 46) divided by total expenditures (defined as DATA 128 plus DATA 46). The industry measure of RND is the median firm value. See Ilyina and Samaniego (forthcoming).

We measure "benchmark" industry growth using the growth rate in sales at the median firm in each industry in Compustat (DATA 12), following Fisman and Love (2007) $\left(G R_{j}\right)$.

Productivity growth is measured using the numbers reported in Jorgenson et al (2007). They also report industry value added growth data for the United States, which will be useful for estimating $\varepsilon$. Equation (14) indicates that, in the benchmark economy, $\varepsilon$ equals one plus the coefficient obtained from regressing value added growth on TFP growth in the benchmark economy. Thus, we can estimate $\varepsilon$ from the Jorgenson et al (2007) data. Using all industries, we find that $\varepsilon=3.21$ (s.d. 0.167). Among the 32 manufacturing industries in the Jorgenson data, the estimate is $\varepsilon=3.75$ (s.d. 0.125), and using 44 non-manufacturing industries in the Jorgenson data it is $\varepsilon=1.85$ (s.d. 0.355 ). In all cases, the estimate is significantly greater than unity. Given that we are using only manufacturing data, we set $\varepsilon=3.75$. 


\section{Calibration}

We now choose parameters for the model economy, to see whether the mechanisms in the model are capable of accounting quantitatively for the finance-R\&D interactions we find in the data. We set period length to equal ten years, as in the data used in Rajan and Zingales (1998), Fisman and Love (2007) and Ilyina and Samaniego (forthcoming). This is roughly the median lifespan of a firm in annual US data - see Samaniego (2010). The parameters we need to calibrate are $\alpha_{l}, \alpha_{x}, \chi, \sigma, \varepsilon, \rho$ as well as the function $n_{j}($.$) and the credit constraints$ $\left\{F_{k}\right\}$. We set $n_{j}(\mu)=-\kappa_{j} \log (1-\mu)$.

\begin{tabular}{l|llllll}
\hline Parameter & $\alpha_{l}$ & $\alpha_{x}$ & $\chi$ & $\rho$ & $\varepsilon$ & $\sigma$ \\
\hline Value & 0.54 & 0.10 & 1.35 & 0.676 & 3.75 & 0.18 \\
\hline
\end{tabular}

Table 1 - Parameter values in the calibrated economy.

The discount factor $\rho$ is set to yield an annual discount rate of $4 \%$. We set $\alpha_{x}=0.1$, so that the income from intermediates produced by R\&D are $10 \%$ of the model economy. ${ }^{19}$ The value of $\alpha_{l}=0.54$, so that non-research labor gets $60 \%$ of the remaining income and the rest goes to entrepreneurs. We select $\chi=1.35$, which leads to a $35 \%$ markup over cost as in Roeger (1995). As discussed above, $\varepsilon=3.75$.

It remains to calibrate the aggregate parameters $\sigma$ and $F_{k}$, as well as industry parameters $\kappa_{j}$ and initial conditions $a_{j k}$. We describe the procedure in the Appendix. In brief, we calibrate $\kappa_{j}$ to match R\&D intensity among publicly traded US firms, and select $\sigma$ so as to match the link between industry TFP growth and R\&D intensity in the data. Initial conditions $a_{j k}$ map into the industry's share of manufacturing in each country. This mapping turns out to require selecting a benchmark industry, and using external information to identify productivity in that industry in each country. We select Textiles as our benchmark industry, and assume that productivity in Textiles is ranked across countries according to $F_{k}$. This assumption reflects the finding of Fisman and Love (2004) that over long periods of time the impact of financial development on growth has an impact on levels as well. ${ }^{20}$ Finally, we select $F_{k}$ by minimizing the distance between R\&D intensity in each country and in the data, given the initial conditions. We do not match the credit-to-GDP ratio nor other measures of financial deepening because we do not model household credit nor business

\footnotetext{
${ }^{19}$ This is roughly the share of GDP that accrues to intangibles in Corrado et al (2006).

${ }^{20}$ We select Textiles (ISIC 321), because data for this industry are available for all countries. Also, it is not relatively R\&D intensive and, as expected, the share of textiles in manufacturing is negatively correlated with the credit-to-GDP ratio, a common measure of financial development (corr. 0.42***). We also used Food (ISIC 313) as a benchmark industry instead of Textiles, obtaining similar results.
} 
credit for purposes other than R\&D, but we check whether our calibrated values of $F_{k}$ do in fact correlate with independent measures of financial development.

Arguably, this procedure assumes that all country differences in RED intensity are due to financing constraints and industry composition, rather than other country differences. As a result, we also perform simulations to assess the importance of this assumption. Specifically, we assume that only some fraction $\varphi$ of $R \& D$ differences across countries is due to financial development. We do this by fixing the highest-R\&D country, and scaling the difference between it and all other countries by a proportion $\varphi$. If $\varphi=1$ then model R\&D matches R\&D in the data, whereas for $\varphi=0$ then all countries have the same R\&D intensity. In practice we set $\varphi \in[0.25,1]$ because, if $\varphi$ is too small, the model is no longer able to match R\&D intensity for some countries because of the influence of industry composition (for example, a country dominated by a low-R\&D intensity industry may not be able to have R\&D spending similar to another country regardless of the value of $F_{k}$.)

\section{Results}

We have calibrated the model economy without recourse to any financial variables. In particular, we obtain values for country credit constraints $F_{k}$ by matching R\&D intensity in the data, rather than by using any exogenous measures of financial development. Nonetheless, our values of $F_{k}$ turn out to be highly correlated with such measures. Table 2 displays the correlations between $F_{k}$ and several financial development indicators, under the assumption that country differences in productivity in the benchmark industry are not large. These correlations are always positive, and often statistically significant. The results are particularly clear when we leave out Israel, which is an outlier because its level of R\&D intensity and industry structure themselves are outliers: it generally has a calibrated value of $F_{k}$ almost three times higher than the next highest. ${ }^{21}$ The financial development measures are the domestic private credit-to-GDP ratio $(C R E)$, drawn from the IMF International Financial Statistics database; bank overhead as a share of assets in 1990 times minus one $(B A N K)$, drawn from the 2006 update of the Beck et al (2000) Database on Financial Development and Structure; the interest rate margin times minus one $(M A R G)$, also from Beck et al (2000); a measure of "loan access" for entrepreneurs without collateral (ACCS), reported

\footnotetext{
${ }^{21}$ This underlines our hypotesis that factors other than financial development may also determine R\&D spending - although there is a strong relationship between rankings by either criterion. For example, Trajtenberg (2002) argues that the Israeli government implemented an unusually intensive R\&D subsidy scheme directed towards R\&D-intensive sectors, which could account for its status as an outlier. Our result are sensitive to such factors because we calibrate financing constraints $F_{k}$ using country R\&D values as well as industry composition. Nonetheless, as we shall see, it is clear that the model generates a systematic link between financial development and both industry and aggregate growth rates even in spite of this.
} 
in the World Economic Forum Global Competitiveness Report (GCR) and based on surveys of executives (see Browne et al (2007) for more details); and a survey-based measure of "financial market sophistication $(S O P H)$, also drawn from the GCR. It is interesting that the results are strongest for the measures not related to financial deepening, consistent with the idea in Beck et al (2008) that only deepening of firm credit is important for growth, not deepening per se.

Having calibrated the model economy, we use the model to generate artificial industry growth rates, and to estimate regression equation (17) with different industry characteristics as independent variables. This is the original specification in Rajan and Zingales (1998), in which the key coefficient is on the interaction between external finance dependence $\left(E F D_{j}\right)$ and financial development, which the model interprets as the impact of financial development on productivity-driven structural change. We also estimate this equation replacing $E F D_{j}$ with $\mathrm{R} \& \mathrm{D}$ intensity $R N D_{j}$, as in Ilyina and Samaniego (forthcoming), and with industry growth $G R_{j}$, as in Fisman and Love (2007).

\begin{tabular}{|l|l|l|l|l|l|l|}
\cline { 2 - 7 } \multicolumn{1}{c|}{} & $(\varphi)$ Share of & \multicolumn{4}{|l|}{ Correlation with fin. dev. measures } \\
\hline Sample & R\&D explained & CRE & BANK & MARG & ACCS & SOPH \\
\hline Including Israel & 0.32 & 0.23 & 0.23 & $0.26^{*}$ & $0.48^{* * *}$ & $0.44^{* *}$ \\
& 0.5 & 0.19 & 0.20 & 0.21 & $0.39^{* *}$ & $0.36^{* *}$ \\
& 1 & 0.28 & 0.25 & $0.27^{*}$ & $0.44^{* * *}$ & $0.44^{* *}$ \\
\hline Excluding Israel & 0.32 & $0.29^{*}$ & $0.30^{*}$ & $0.35^{* *}$ & $0.69^{* * *}$ & $0.60^{* * *}$ \\
& 0.5 & $0.26^{*}$ & $0.31^{*}$ & $0.33^{* *}$ & $0.69^{* * *}$ & $0.59^{* * *}$ \\
& 1 & $0.43^{* * *}$ & $0.39^{* *}$ & $0.42^{* *}$ & $0.74^{* * *}$ & $0.72^{* * *}$ \\
\hline
\end{tabular}

Table 2 - Correlations between $F_{k}$ in the model economy and financial development measures.

Results are reported when the difference in benchmark industry productivity across the most and least financially developed countries is a quarter. Figure 2 shows that this parameterization displays an empirically significant interaction coefficient. when $\varphi$ is relatively low. Financial development measures are described in the text - see also Ilyina and Samaniego (forthcoming).

To estimate this regression, we use as independent variables the industry share in the data (which is the same as in the model), and also the values of the interaction terms $R N D_{j} \times F_{k}$, $E F D_{j} \times F_{k}$ or $G R_{j} \times F_{k}$ from the data, using the credit-to-GDP ratio as a measure of $F_{k}$ as in the empirical literature. However, the independent variable (industry growth) is generated by the calibrated model. Since financial constraints in the model economy were constructed without using the credit to GDP ratio from the data, there is nothing in the 
calibration procedure to indicate that the model would necessarily generate statistically significant interaction coefficients when regressed on interaction terms constructed using actual data.

Results are reported in Figure 2. Countour lines reflect the values of interaction coefficients $\beta_{F, R N D}, \beta_{F, E F D}$ and $\beta_{F, G R}$, depending on the panel. Interaction coefficients for each of these variables are generally positive, though smaller (and sometimes negative) when we assume more dispersion of initial conditions. The interaction in Proposition 5 is offset by the fact that industries that are far behind the technological frontier grow disproportionately fast. Towards the right of the panels in Figure 2, this second effect is very strong, so that the local approximation implicit in the regression is no longer a good approximation to model dynamics.
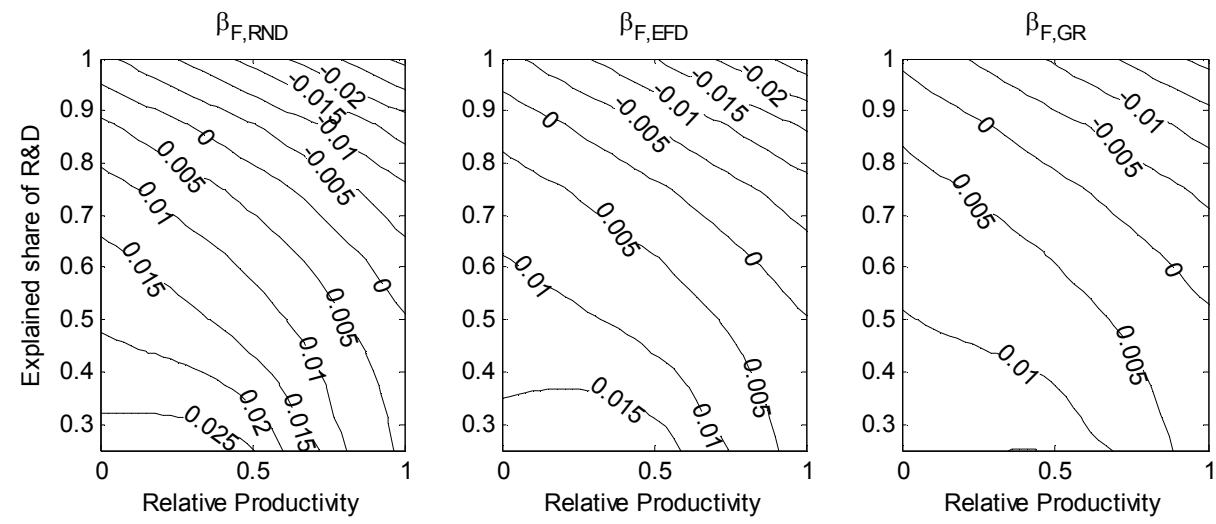

Figure 2 - Interaction coefficient in equation (17) when

financial development is interacted with R\&D intensity $\left(R N D_{j}\right)$, external finance dependence $\left(E F D_{j}\right)$ or industry growth $\left(G R_{j}\right)$. Financing constraints are measured by matching R\&D intensity at the country level. The vertical axis displays the share of R\&D country differences that is assumed to be accounted for by financial development. The horizontal axis represents the assumed difference in relative productivity across countries with different levels of financial development, with zero indicating no differences. The contour lines are the values of the interaction coefficient in (17) when industry growth is generated using the calibrated model economy.

In Ilyina and Samaniego (forthcoming), the interaction coefficient of R\&D intensity and financial development (standardized by their means and standard deviations) is 0.038, whereas 
the interaction coefficient of EFD and financial development is $0.033 .^{22}$ Interaction coefficients in the calibrated model are smaller but of similar magnitude so long as we assume that financing constraints account for about one quarter of cross-country dispersion in research spending, and that differences in initial conditions in the benchmark industry are not too large - see Figure 2. The highest coefficient for $\beta_{F, R N D}$ using model-generated industry growth data is 0.275 .

As an alternative calibration strategy, instead of setting $F_{k}$ to match country R\&D spending, we set $F_{k}$ so as to match predicted R\&D spending based on a regression of R\&D on the credit-to-GDP ratio - see Figure 3. This amounts to assuming that the ranking of $F_{k}$ is given by a standard measure of financial development, whereas its magnitude is given by R\&D spending - again following the proposition in Beck et al (2008) that only a portion of financial deepening is relevant for economic growth. In this case, the model yields coefficients of $\beta_{F, R N D}$ as high as 0.6, agan when financing constraints account for about one quarter of cross-country dispersion in research spending. Thus, we find that the model can reproduce the interaction coefficients in the empirical literature so long as there is sufficient (though not excessive) heterogeneity of initial conditions.
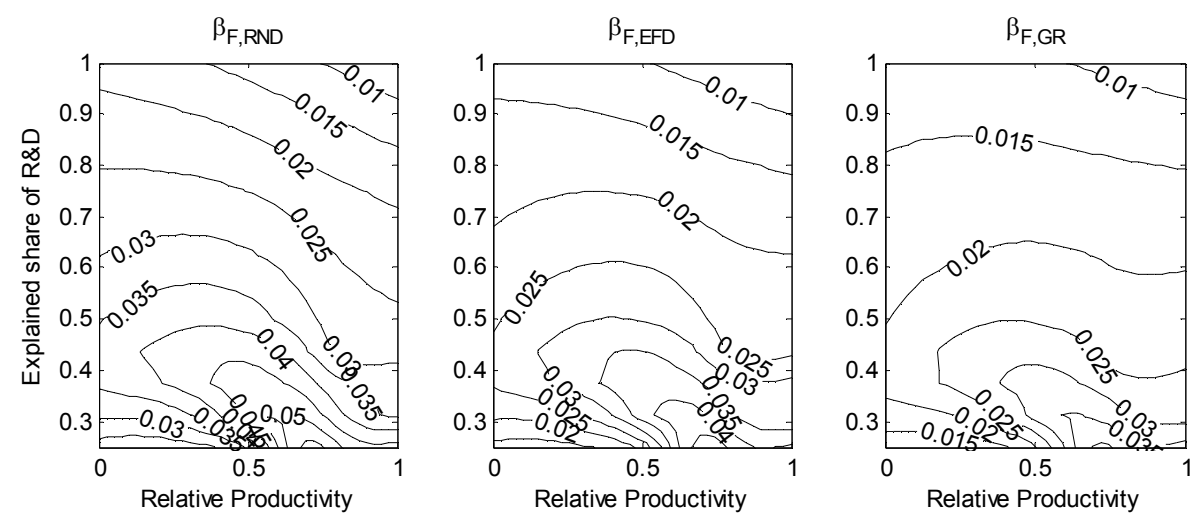

Figure 3 - Interaction coefficient in equation (17) when

financial development is interacted with R\&D intensity $\left(R N D_{j}\right)$, external finance dependence $\left(E F D_{j}\right)$ or industry growth $\left(G R_{j}\right)$. Financing constraints are measured using the part of R\&D intensity at the country level that is predicted by the credit-to-GDP ratio $\left(C R E_{k}\right)$.

\footnotetext{
${ }^{22}$ We compare to the estimates in Ilyina and Samaniego (forthcoming) - and not Rajan and Zingales (1998) - because RZ use a finer industry classification which mainly disaggregates the most R\&D intensive industries. Their coefficients are larger, as is to be expected from disaggregating on the industries with the greatest financial need and R\&D intensity. A nonlinearity of this kind is to be expected since firms with need for external finance or R\&D intensity below some threshold may be insensitive to financial conditions.
} 
We also adopted an alternative strategy for testing the model: estimating equation (17) using actual industry growth data from INDSTAT3, but using the model-generated measure of financing constraints $F_{k}$ in the interaction term instead of the credit-to-GDP ratio. Using the measure of $F_{k}$ from the preferred calibration, the interaction coefficient of R\&D intensity was $0.28^{* *}$ (s.d. 0.127 ), very close to the interaction coefficient obtained when using CRE as a measure of $F_{k}$ and using model-generated industry growth values instead of actual data. The interaction coefficient for $E F D_{j}$ in this case was $0.26^{* *}$ (s.d. 0.129).

\section{E Mapping from growth to productivity}

What are the quantitative implications of the estimated values for $\varepsilon$ ? Ilyina and Samaniego (forthcoming) find that $\beta_{F, R N D}=0.038$ in the 1990s. The country at the 75 th percentile of financial development (credit-to-GDP ratio) is France, whereas Egypt is at the 25th. The industry at the 75th percentile of $R N D_{j}$ is Industrial Chemicals, and Food Products is at the 25th. If financial development in an average country were to improve from the level of Egypt to the level of France, Industrial Chemicals would grow 1.1\% faster annually than Food Products. If $\varepsilon=3.75$, then this $1.1 \%$ growth differential reflects an additional $0.4 \%$ productivity growth differential due to financial development.

A value of $\varepsilon$ not only converts the empirical interaction coefficients into a statement about industry productivity differences. If financial development results in no technological regress in any industry, then it also translates into a lower bound on the aggregate productivity gain from a given increase in financial development, computing the productivity differential in each industry for different levels of financial development and aggregating across industries. $^{23}$ Suppose, for example, that financial development were to improve in all countries to the highest level among countries in the sample (Japan). Adding across all industries in each country using the industry shares reported in INDSTAT $3,{ }^{24}$ and assuming that in absolute terms no industry deteriorates in terms of productivity growth, this implies that increasing the level of financial development to that of the most developed economy raises manufacturing productivity by between $0.5 \%$ and $1.5 \%$ annually depending on the country, with a median of $0.9 \%$. According to the BEA, US productivity growth this decade has averaged $2.6 \%$, so these numbers are economically significant.

\footnotetext{
${ }^{23}$ Since there exist industries with little $\mathrm{R} \& \mathrm{D}$, little external finance and little technical change (e.g. Tobacco, ISIC code 314) then this lower bound may in fact be a reasonable estimate of the productivity impact of financial development.

${ }^{24}$ As discussed in Jorgenson et al (2007) the way to aggregate productivity is using Domar weights, not shares of value added. We compute Domar weights assuming that industry value added equals half of gross output: see Ngai and Samaniego (2009).
} 


\section{F Further results}

In Ilyina and Samaniego (2009) and the technical appendix, we report further results.

1. It is central to the paper that the model builds on empirically-based relationships between the use of finance, technological characteristics, and productivity growth. We report evidence supporting several assumptions and implications of the model. This includes a positive link between R\&D intensity and financial need; a positive link between R\&D intensity and the inability to raise funds (asset intangibility and firmlevel asymmetric information); a positive link between $R \& D$ intensity and industry growth in the benchmark economy (taken to be the US); and a positive link between R\&D intensity, TFP growth, and industry growth in the benchmark economy. Several of these findings also support the structure of the related one-sector AHM model.

2. We estimate equation (16), which is similar to equation (17) in Rajan and Zingales (1998) except for some additional second order terms. We find that the interaction term of R\&D intensity with financial development is positive and statistically significant for a variety of measures of financial development.

3. AHM derive an empirical prediction of their one sector model in the form of a positive interaction between the level of financial development and initial GDP. It is not clear that this result would necessarily be preserved in a multi-sector context. Nonetheless, we find that model-generated GDP values yield a statistically significant coefficient when we focus on the manufacturing sector.

4. Interestingly, the model is able to reproduce the well known pattern of structural change observed by Imbs and Wacziarg (2003), that industrial specialization first decreases and subsequently increases over time as countries develop. This pattern of "stages of diversification" is typically interpreted in terms of the diversification of productive risk in a small open economy. We find that even a closed economy without aggregate uncertainty may display this pattern, if initial conditions skew a country's industry composition away from the industries that dominate in the long run as a matter of productivity-induced structural change. By compressing industry differences in productivity growth rates, the role of financial underdevelopment is to delay the turning point after which specialization begins to increase again. Thus, the model can encompass two important empirical regularities regarding structural change: the industry growth differences found by Rajan and Zingales (1998), and also the "stages of diversification" dynamics in Imbs and Wacziarg (2003), with the former implying a deceleration of the latter. 


\section{Conclusion}

We present a model in which financial development and industry characteristics such as the cost of research jointly determine industry growth rates. In equilibrium, financial development disproportionately increases growth in industries that are more $R \& D$ intensive. Equilibrium industry dynamics in the model economy map into well-known empirical specifications of the link between finance and industry growth, providing new insights into the interpretation of these regressions in terms of the effect of financial development on convergence through technology transfer. Indeed, given that the industries that most draw on external finance are also the most R\&D-intensive and those with the most rapid productivity growth, our model shows that the Rajan and Zingales (1998) result in fact indicates a new channel whereby financial markets encourage growth: the accelerated reallocation of resources towards the most high-tech industries.

The paper underscores the importance of general equilibrium analysis for understanding the impact of financial development upon resource allocation across industries. Since financial underdevelopment compresses industry differences in productivity, it slows reallocation of resources among these industries - but whether this reallocation is towards or away from the industries with the most rapidly expanding technological frontiers depends on preference parameters - specifically, the elasticity of substitution across goods.

We see at least two interesting directions for future research. First, we have held the level of financial development constant, as we view financial development as being a function of "deep" institutions such as property rights and contract enforcement (Acemoglu and Johnson (2005)), which change rarely. However, it would be interesting to study the behavior of the economy after institutional reform, which might increase or decrease the level of financial development and lead to interesting transition dynamics. Second, the paper abstracts from trade flows, which Manova (2008) finds can be affected by financial liberalization. It remains to be shown whether differences in export structure can be related to the level of financial development, in which case trade could complement the mechanisms underlined in this paper, if disproportionate productivity improvements in $R \& D$ intensive industries allow them to disproportionately increase their share of the global - not just the domestic - market.

\section{References}

Acemoglu, Daron, and Simon Johnson. 2005. Unbundling Institutions. Journal of Political Economy, Vol. 113 No. 5, 949-995.

Acemoglu, Daron and Fabrizio Zilibotti. 2001. Productivity Differences. Quarterly 
Journal of Economics 116 No.2, pp. 563-606.

Aghion, Philippe, Abhijit V. Banerjee and Thomas Piketty, 1999, "Dualism and macroeconomic volatility," Quarterly Journal of Economics, Vol. 114 No. 4, pp. 1359-1397.

Aghion, Philippe, Peter Howitt and David Mayer-Foulkes, 2005, "The Effect of Financial Development on Convergence: Theory and Evidence," Quarterly Journal of Economics, Vol. 120 No. 1, pp. 173-222.

Beck, Thorsten, Asli Demirgüç-Kunt and Ross Levine, 2000, "A New Database on Financial Development and Structure," World Bank Economic Review, Vol. 14, pp. 597-605.

Beck, Thorsten, Berrak Buyukkarabacak, Felix Rioja and Neven Valev. 2008. "Who gets the credit? And does it matter? Household vs firm lending accross countries." Mimeo: Tilburg University.

Bencivenga, Valerie R. and Bruce D. Smith, 1991, "Financial Intermediation and Endogenous Growth," Review of Economic Studies, Vol. 58 No. 2, pp. 195-209.

Browne, Ciara, Richard Bryden, Mercedes Delgado and Thierry Geiger. 2008. Executive Opinion Survey: Capturing the Voice of the Business Community. Geneva: World Economic Forum.

Buera, Francisco J., Joseph P. Kaboski and Yongseok Shin, 2008, "Finance and Development: A Tale of Two Sectors." Mimeo: UCLA Department of Economics.

Caballero, Ricardo J. and Adam B. Jaffe, 1993. "How High are the Giants' Shoulders: An Empirical Assessment of Knowledge Spillovers and Creative Destruction in a Model of Economic Growth," NBER Macroeconomics Annual 1993, Volume 8, pages 15-86.

Carlin, Wendy and Colin Mayer, 2003, "Finance, investment, and growth," Journal of Financial Economics, Vol. 69 No. 1, pp. 191-226.

Ciccone, Antonio and Elias Papaioannou, 2006, "Adjustment to Target Capital, Finance and Growth." Mimeo: Universitat Pompeu Fabra.

Ciccone, Antonio and Elias Papaioannou, 2010, "Estimating Cross-Industry Cross-Country Models Using Benchmark Industry Characteristics." Mimeo: Universitat Pompeu Fabra.

Cohen, Wesley M. and Richard C. Levin, 1989, "Empirical studies of innovation and market structure." In R. Schmalensee \& R. Willig (ed.) Handbook of Industrial Organization, Chapter 18, pp. 1059-1107.

Cohen, Wesley M. and Daniel A. Levinthal, 1990, "Absorptive Capacity: A New Perspective on Learning and Innovation," Administrative Science Quarterly, Vol. 35, pp. 128-152.

De la Fuente, Angel and Jose María Marín, 1996, "Innovation, Bank Monitoring, and Endogenous Financial Development," Journal of Monetary Economics, Vol. 38 No. 2, pp. 269-301.

Evans, David S. and Boyan Jovanovic, 1989, "An Estimated Model of Entrepreneurial 
Choice under Liquidity Constraints," Journal of Political Economy, Vol. 97 No. 4, pp. 808-27.

Fisman, Raymond and Inessa Love, 2004, "Financial Development and Growth in the Short and Long Run," NBER Working Paper No. 10236.

Fisman, Raymond and Inessa Love, 2007, "Financial Dependence and Growth Revisited," Journal of the European Economic Association, Vol. 5 No. 2-3, pp. 470-479.

Greenwood, Jeremy and Boyan Jovanovic, 1990, "Financial Development, Growth, and the Distribution of Income," Journal of Political Economy, Vol. 98 No. 5, pp. 1076-1107.

Griffith, Rachel, Stephen Redding and John Van Reenen, 2004, "Mapping the Two Faces of R\&D: Productivity Growth in a panel of OECD industries," Review of Economics and Statistics, Vol. 86 No. 4, pp. 883-895.

Hall, Bronwyn H, 2005, "The Financing of Innovation," In Shane, S. (ed.), Blackwell Handbook of Technology and Innovation Management, Oxford: Blackwell Publishers, Ltd.

Ilyina, Anna and Roberto Samaniego, 2009, "A Multi-industry Model of Growth with Financing Constraints." IMF Working Paper 09/119.

Ilyina, Anna and Roberto Samaniego, Forthcoming, "Technology and Financial Development." Journal of Money, Credit and Banking.

Imbs, Jean and Romain Wacziarg, 2003, "Stages of Diversification," American Economic Review, Vol. 93 No. 1, pp. 63-86.

Jorgensen, Dale, Mun S. Ho, Jon Samuels and Kevin J. Stiroh, 2007, "Industry Origins of the American Productivity Resurgence," Economic Systems Research, Vol. 19 No. 2, pp. 229-252.

Jovanovic, Boyan and Yaw Nyarko, 1996, "Learning by Doing and the Choice of Technology," Econometrica, Vol. 64 No. 6, pp. 1299-1310.

Khan, Aubhik, 2001, "Financial Development and Economic Growth," Macroeconomic Dynamics, Vol. 5, pp. 413-33.

King, Robert G. and Ross Levine, 1993, "Finance and Growth: Schumpeter Might be Right," Quarterly Journal of Economics, Vol. 108 No. 3, pp. 717-37.

Kiyotaki, Nobuhiro and John Moore, 1997, "Credit Cycles," Journal of Political Economy, Vol. 105 No. 2, 211-48.

Luttmer, Erzo G.J., 2007, "Selection, Growth, and the Size Distribution of Firms," Quarterly Journal of Economics, Vol. 122 No. 3, pp. 1103-1144.

Manova, Kalina, 2008. "Credit Constraints, Equity Market Liberalizations and International Trade." Journal of International Economics 76, 33-47.

Morales, María F. 2003. Financial Intermediation in a Model of Growth through Creative Destruction. Macroeconomic Dynamics, 7: 363-393 
Ngai, Rachel and Christopher Pissarides, 2007, "Structural Change in a Multisector Model of Growth," American Economic Review, Vol. 97 No. 1, pp. 429-443.

Ngai, Rachel and Roberto Samaniego, 2009, "Mapping Prices into Productivities in Multi-sector Growth Models" Journal of Economic Growth 14(3), September 2009, 183-205.

Ngai, Rachel and Roberto Samaniego, 2011, "Accounting for Research and Productivity Growth Across Industries," forthcoming, Review of Economic Dynamics.

Rajan, Raghuram G. and Luigi Zingales, 1998, "Financial Dependence and Growth," American Economic Review, Vol. 88 No. 3, pp. 559-586.

Rancière, Romain and Aaron Tornell, 2009, "Financial Liberalization, Boom-Bust Cycles and Production Efficiency," Mimeo: UCLA.

Roeger, Werner. 1995. Can Imperfect Competition Explain the Difference between Primal and Dual Productivity Measures? Estimates for U.S. Manufacturing. Journal of Political Economy 103(2), 316-330.

Samaniego, Roberto, 2010, "Entry, Exit and Investment-Specific Technical Change," American Economic Review, 100, No. 1, 164-192.

Terleckyj, Nestor E., 1980, "What do R\&D numbers tell us about Technological Change?" American Economic Review, Vol. 70 No. 2, pp. 55-61.

Trajtenberg, Manuel, 2002, "Government Support for Commercial R\&D: Lessons from the Israeli Experience." A.B. Jaffe, J. Lerner and S. Stern (eds), Innovation Policy and the Economy 2, pp. 79-134, (the MIT Press: Cambridge).

World Bank, 2007. World Development Indicators 2007. http://hdrstats.undp.org/indicators, last checked 09/09/2009.

World Economic Forum, 2008, "Executive Opinion Survey and Financial Development Report," London: Palgrave Macmillan.

Wurgler, Jeffrey. 2000. "Financial Markets and the Allocation of Capital," Journal of Financial Economics 58, 187-214.

\section{A Derivations and Proofs}

\section{A Resource constraints}

Because of the production structure in (5), for any unit of good $j$ used in consumption, an additional volume of good $j$ is required for the production of customized intermediates. This volume depends upon the amount of intermediates used $x_{j t}(i)$ and on the number of units of $j$ required for each intermediate $x_{j t}(i)$, which averages $1+\left(1-\mu_{j t}\right) \chi$ because $\rightarrow$ not all intermediates are successfully customized at the frontier productivity. From the firm's first 
order conditions, the number of units of $j$ demanded as intermediates per unit of output is $\frac{\int x_{j t}(i) d i}{y_{j t}}=\frac{\alpha_{x}}{\chi}$. Hence, for each unit of good $j$ produced, the number of units of $j$ used to produce intermediates is $I_{j t}=\left(1+\left(1-\mu_{j t}\right) \chi\right) \frac{\alpha_{x}}{\chi}$.

If $\bar{c}_{j t}$ units of good $j$ are consumed in total, then $\bar{c}_{j t} I_{j t}$ units of $j$ are required as intermediates to produce them. In turn, each of the $\bar{c}_{j t} I_{j t}$ units of $j$ used to make intermediates itself requires a similar proportion $I_{j t}$ for intermediate use. As a result, market clearing requires that: ${ }^{25}$

$$
M_{j t} y_{j t}=\bar{c}_{j t} \frac{1}{1-I_{j t}} .
$$

where $M_{j t}$ is the number of firms in industry $j$. This is also the feasibility condition for each final good: $M_{j t} y_{j t}$ is gross output of $j$, while $\bar{c}_{j t} \frac{1}{1-I_{j t}}$ is total intermediate and final demand.

In any period, there is quantity 2 of labor available. Labor demand is entrepreneurial labor $\sum_{j} M_{j t}$, production labor $\sum_{j} M_{j t} l_{j t}$ and labor in research $\sum_{j} M_{j t} \kappa_{j} n\left(\mu_{j t}\right) / a_{j t}$. Thus

$$
2 \geq N_{t}^{R}+\sum_{j} M_{j t}\left(1+l_{j t}\right)+\sum_{j} M_{j t} \kappa_{j} n\left(\mu_{j t}\right) / a_{j t}
$$

Suppose each agent has a name $i$ on the interval $[t, t+1)$, where $t$ is their date of birth. Let $b_{i t}$ be the savings of agent $i$ at date $t$. Market clearing for financial markets requires that

$$
\int_{i \in[t, t+1)} b_{i t} d i=0
$$

The feasibility constraint for the economy is that spending should not exceed output, i.e. $Y_{t} \geq \sum_{j} q_{j t} \bar{c}_{j t}$.

If $N_{t}^{R} \geq N_{t}^{E}$, then some researchers are unmatched, so $M_{t}=N_{t}^{E}$ and the expected return to becoming a researcher is $\Pi_{t}^{R} \equiv \frac{\sum_{j} M_{j t} \Pi_{j t}^{R}\left(S_{t}\right)}{N_{t}^{R}}$, since for unmatched agents there is no income from research (only from bonds). Hence, optimal occupational choice requires:

$$
N_{t}^{R}=\sum_{j} M_{j t} \Pi_{j t}^{R}\left(S_{t}\right)
$$

\section{B Productivity dynamics in the model}

Recall that the return to entrepreneurship $\Pi_{t}^{E}=1$. Since the production technology exhibits decreasing returns to scale, and since the share of entrepreneurial returns is constant

\footnotetext{
${ }^{25}$ An alternative interpretation is that $\left(\mu_{j t}+1-\chi \mu_{j t}\right) \int x_{j t}(i) d i$ is "foregone output," so that final output for a given firm is $y_{j t}\left[1-I_{j t}\right]$. Thus, final consumption of $j$ is $c_{j t}=M_{j t} y_{j t}\left[1-I_{j t}\right]$ and, in this case too, equation (18) holds.
} 
over time, this condition determines the equilibrium link between goods prices and industry productivity.

Lemma 2 If $N_{t}^{R} \geq N_{t}^{E}$, there are unique positive values $\psi^{*}$ and $l^{*}$ such that $q_{j t} A_{j t}=\psi^{*}$ and $l_{j t}=l^{*}$ for all $j, t$.

The entrepreneur cannot invest more than a finite multiple $F$ of her available funds $S_{t}$. Since $S_{t} \leq 1$, the entrepreneur is constrained if and only if $\tilde{n}_{j}\left(\mu_{j}^{*}\right)>a_{j, t-1} F$.

To characterize equilibrium industry productivity dynamics we consider two loci. One describes the dynamics of a firm that invests the optimal level of research input. The other describes the dynamics of a firm that devotes all available financial resources to research, regardless of whether or not this is unconstrained-optimal. "Available financial resources" refers to $F w_{t}$. The firm will be on the latter locus, unless available financial resources exceed unconstrained-optimal research spending.

Let $\tilde{\mu}_{j}(\cdot)$ be the inverse of $\tilde{n}_{j}(\cdot)$. Suppose that $F$ is very large - large enough that financing constraints do not bind for any $j$. Optimal investment is given by the first order condition to problem (10). Relative productivity $a_{j t}$ follows the law of motion $a_{j t}=H_{j}^{1}\left(a_{j, t-1}\right)$ where, using (12), the function $H_{j}^{1}$ is given implicitly by

$$
a_{j t}=\tilde{\mu}_{j}\left(\frac{\pi a_{j, t-1}}{a_{j t}}\right)+\frac{\left[1-\tilde{\mu}_{j}\left(\frac{\pi a_{j, t-1}}{a_{j t}}\right)\right]}{g_{j}} a_{j, t-1} .
$$

where $\pi \equiv \rho \pi_{j t} a_{j t}$ is a constant function of parameters that does not depend on $j$ nor $t$. Also, $a_{j t}$ converges to the steady state value $a_{j}^{*}$ where, using (12) and (13),

$$
a_{j}^{*} \equiv \frac{\sigma \mu_{j}^{*}+1}{\sigma+1}<1
$$

where $\mu_{j}^{*}<1$ is defined implicitly by

$$
\pi=\kappa_{j} n^{\prime}\left(\mu_{j}^{*}\right)
$$

given a constant $\pi$ that does not differ across industries.

Next, suppose that researchers devote all their available financial resources towards research. Then, $\mu_{j k}=\tilde{\mu}_{j}\left(F a_{j, t-1}\right)$. Productivity dynamics in this case are given by $a_{j t}=H_{j}^{2}\left(a_{j, t-1}\right)$ where again using $(12)$,

$$
H_{j}^{2}\left(a_{j, t-1}\right)=\tilde{\mu}_{j}\left(F a_{j, t-1}\right)+\frac{\left[1-\tilde{\mu}_{j}\left(F a_{j, t-1}\right)\right]}{g_{j}} a_{j, t-1} .
$$


Finally, since equilibrium research spending will equal the unconstrained optimum unless the latter exceeds the borrowing limit, in equilibrium $a_{j t}$ is given by:

$$
a_{j t}=H_{j}\left(a_{j, t-1}\right) \equiv \min \left\{H_{j}^{1}\left(a_{j, t-1}\right), H_{j}^{2}\left(a_{j, t-1}\right)\right\}
$$

The function $H_{j}\left(a_{j, t-1}\right)$ determines the link between financing constraints and industry productivity dynamics.

Lemma 3 The functions $H_{j}^{1}(\cdot)$ and $H_{j}^{2}(\cdot)$ have the following properties:

(i) $H_{j}^{1}(\cdot)$ does not depend on $F ; H_{j}^{2}(\cdot)$ is strictly increasing in $F$ for all $a_{j, t-1}>0$

(ii) $H_{j}^{1}(\cdot)$ and $H_{j}^{2}(\cdot)$ are strictly increasing, and $H_{j}^{2}(\cdot)$ is strictly concave.

(iii) The function $H_{j}^{1}(\cdot)$ has two fixed points, at the values $a_{j, t-1} \in\left\{0, a^{*}\right\}$.

(iv) The function $H_{j}^{2}(\cdot)$ has two fixed points, at the values $a_{j, t-1} \in\left\{0, a^{* *}\right\}$, where $a^{* *}$ is increasing in $F$.

(v) for sufficiently low $F, \lim _{a \rightarrow 0} \frac{d H_{j}^{1}(a)}{d a}>\lim _{a \rightarrow 0} \frac{d H_{j}^{2}(a)}{d a}$.

Based on Lemma 3, the space of parameter values can be divided into three regions, in which productivity dynamics behave differently. ${ }^{26}$

Region 1 For sufficiently high levels of $F, \mu_{j t} \rightarrow \mu_{j}^{*}$ and $a_{j t} \rightarrow a_{j}^{*}$. Higher financial development shifts $H_{j}^{2}$ upwards, and may affect industry growth rates along the convergence path, for the range where $H_{j}^{1}\left(a_{j, t-1}\right)>H_{j}^{2}\left(a_{j, t-1}\right)$, but it does not affect the limit $a_{j}^{*}$. This is similar to Figure $I$ in Aghion et al (2005).

Region 2 For intermediate levels of $F, \mu_{j t} \rightarrow \mu_{j}^{*}$ but $a_{j t} \rightarrow a_{j}^{* *}<a_{j}^{*}$. Higher financial development shifts $H_{j}^{2}$ upwards, and can have a positive marginal effect on industry growth rates along the convergence path, and also on the limit $a_{j}^{* *}$. This is similar to Figure II in Aghion et al (2005).

Region 3 For sufficiently low levels of $F, a_{j t} \rightarrow 0$, and productivity growth converges to a value below $g_{j}$ that is increasing in $F$. Greater financial development within this range would still have a positive effect on productivity growth, although it would remain below $g_{j}$ in the long run. ${ }^{27}$ This is similar to Figure $I I I$ in Aghion et al (2005).

\footnotetext{
${ }^{26}$ In Region 1 , then $H_{j}^{1}$ and $H_{j}^{2}$ cross above the $45^{\circ}$ line: $F \geq \frac{\kappa_{j} n\left(\mu_{j}^{*}\right)}{(1+r) a_{j}^{*}}$. In Region $2, H_{j}^{1}$ and $H_{j}^{2}$ cross below the $45^{\circ}$ line, and $\left.\frac{\partial H_{j}^{2}(a)}{\partial a}\right|_{a=0}>1: F \in\left(\frac{g_{j}-1}{(1+r) \tilde{\mu}_{j}^{\prime}(0) g_{j}}, \frac{\kappa_{j} n\left(\mu_{j}^{*}\right)}{(1+r) a_{j}^{*}}\right)$. In Region 3 , then $\left.\frac{\partial H_{j}^{2}(a)}{\partial z}\right|_{a=0} \leq 1$ : $F \leq \frac{g_{j}-1}{(1+r) \tilde{\mu}_{j}^{\prime}(0) g_{j t}}$

${ }^{27}$ To see this, observe that productivity growth equals $g_{j} \frac{a_{j, t+1}}{a_{j t}}$ and that, in $\operatorname{Region} 3, \lim _{t \rightarrow \infty} \frac{a_{j, t+1}}{a_{j t}}=$ $\lim _{t \rightarrow \infty} \frac{\tilde{\mu}_{j t}}{a_{j, t-1}}+\frac{1}{g_{j}}=\frac{F(1+r)}{1-\alpha_{x}} \frac{1}{\kappa_{j} n^{\prime}(0)}+\frac{1}{g_{j}}$.
} 
For each $j$, there is a value $\underline{F}_{j}$ such that industry $j$ lies in Region 3 for $F \leq \underline{F}_{j}$, and a value $\bar{F}_{j}$ such that industry $j$ lies in Region 2 for $F \in\left(\underline{F}_{j}, \bar{F}_{j}\right) . \bar{F}_{j}$ is given by optimal R\&D spending in the benchmark economy so, over the empirically relevant range $\left(\kappa_{j} \geq \kappa^{*}\right), \bar{F}_{j}$ is negatively related to $\kappa_{j}$. The lower the optimal R\&D in a given industry $j$, the less likely it is to be finance-constrained for a given borrowing limit $F$, as in Figure 1.

\section{Proofs}

Proof of Lemma 1. The result concerning $\kappa^{* *}$ follows from the fact that $n^{\prime}(0)>0$ so that for sufficiently large $\kappa_{j} \pi \rho<\kappa_{j} n^{\prime}(\mu)$ for all $\mu \geq 0$ so it is not profitable to conduct research. If $\kappa_{j}<\kappa^{* *}, \mu_{j}^{*}$ is given by the condition $\pi=\kappa_{j} n^{\prime}\left(\mu^{*}\right)$ so that $\mu_{\kappa}^{*}=-\frac{n^{\prime}\left(\mu^{*}\right)}{\kappa_{j} n^{\prime \prime}\left(\mu^{*}\right)}<0$ if $n^{\prime}>0$, $n^{\prime \prime}>0$. Total R\&D spending in the benchmark economy is $\kappa_{j} n\left(\mu_{j}^{*}\right) / a_{j}^{*}$ so, suppressing asterisks,

$$
\frac{d \kappa_{j} n(\mu) / a}{d \kappa_{j}}=\frac{\sigma+1}{(\sigma \mu+1)}\left[n(\mu)-\frac{\left[n^{\prime}(\mu)\right]^{2}}{n^{\prime \prime}(\mu)}\right]+\mu_{\kappa} \sigma \kappa_{j} n(\mu) \frac{\sigma+1}{(\sigma \mu+1)^{2}}
$$

Since $\mu_{\kappa}<0$, the sign of this derivative hinges on the sign of $X\left(\kappa_{j}\right) \equiv \frac{d \kappa_{j} n(\mu)}{d \kappa_{j}}=n(\mu)-\frac{\left[n^{\prime}(\mu)\right]^{2}}{n^{\prime \prime}(\mu)}$. Note that $\lim _{\kappa_{j} \rightarrow \kappa^{* *}} \mu_{j}^{*}=0$, so that $\lim _{\kappa_{j} \rightarrow \kappa^{* *}} X\left(\kappa_{j}\right)=-\frac{\left[n^{\prime}(0)\right]^{2}}{n^{\prime \prime}(0)}<0$. On the other hand, $\lim _{\kappa_{j} \rightarrow 0} \kappa_{j} n\left(\mu_{j}^{*}\right) / a_{j}^{*}=0$ also, so that there exists $\kappa^{*}>0$ such that R\&D intensity and $\kappa_{j}$ are strictly negatively correlated if $\kappa_{j} \in\left[\kappa^{*}, \kappa^{* *}\right]$ (and equal to zero if $\kappa_{j}>\kappa^{* *}$ ), so R\&D intensity, $\mu_{j}^{*}$ and $g_{j}^{*}$ are positively correlated in this range.

Proof of Lemma 2. There is perfect competition in goods markets, so the demand function for intermediates is

$$
x_{j t}(i)=A_{j t}(i)\left(\frac{\alpha_{x} l_{j t}^{\alpha_{l}}}{\chi}\right)^{\frac{1}{1-\alpha_{x}}} .
$$

For labor, the firm's first order condition is

$$
\alpha_{l} q_{j t} y_{j t}=l_{j t} w_{t}
$$

Let labor be the numeraire, so that $w_{t}=1$. Placing (27) into (5), we have $y_{j t}=A_{j t} l_{j t}^{\frac{\alpha_{l}}{1-\alpha_{x}}} \zeta$ where $\zeta=\left(\frac{\alpha_{x}}{\chi}\right)^{\frac{\alpha_{x}}{1-\alpha_{x}}}$. So, using $(28)$,

$$
\alpha_{l} q_{j t} A_{j t} l_{j t}^{\frac{\alpha_{l}}{1-\alpha_{x}}-1} \zeta=w
$$


This implies that $\alpha_{l} q A_{j t} l_{j t}^{\frac{\alpha_{l}}{1-\alpha_{x}}-1} / w_{t}=1$ in all industries.

Allowing new entrepreneurs to choose their sector of entry implies that expected profits in all sectors are equal, so $\Pi_{j t}^{E}=q_{j t} y_{j t}\left(1-\alpha_{l}-\alpha_{x}\right)=q_{j t} A_{j t} \frac{\alpha_{j t}^{1-\alpha_{x}}}{\zeta}\left(1-\alpha_{l}-\alpha_{x}\right)$ is constant across industries. This implies that $l_{j t}$ is also equal across sectors, as $l_{j t}=$ $\alpha_{l} \Pi_{j t}^{E} /\left(1-\alpha_{l}-\alpha_{x}\right)$, and hence $\Pi_{j t}^{E}=q_{j t} A_{j t}\left[\frac{\alpha_{l} \Pi_{j t}^{E}}{1-\alpha_{l}-\alpha_{x}}\right]^{\frac{\alpha_{l}}{1-\alpha_{x}}} \zeta\left(1-\alpha_{l}-\alpha_{x}\right)$. Note that this implies that $q_{j t} A_{j t}$ is constant across industries, so that there are functions $K$ and $G$ such that $\Pi_{j t}^{E}=K\left(q_{j t} A_{j t}\right)$, and $l_{j t}=G\left(q_{j t} A_{j t}\right)=G_{1}\left(q_{j t} A_{j t}\right)^{G_{2}}$. Since $\Pi_{j t}^{E}=1$ at all dates, we have that $q_{j t} A_{j t}=\psi^{*}$, where $\psi^{*}=\left[\alpha_{l}^{\alpha_{l}} \zeta^{1-\alpha_{x}}\left(1-\alpha_{l}-\alpha_{x}\right)^{1-\alpha_{x}-\alpha_{l}}\right]^{-\frac{1}{1-\alpha_{x}}}$. Hence optimal labor input $l^{*}$ is $l^{*}=\alpha_{l} /\left(1-\alpha_{l}-\alpha_{x}\right)$. Profits from a successful innovation are $\pi_{j t}(i)=A_{j t}^{*}(i)\left(\frac{\alpha_{x}\left(l^{*}\right)^{\alpha_{l}}}{\chi}\right)^{\frac{1}{1-\alpha_{x}}}[\chi-1] q_{j t}=\left(\frac{\alpha_{x}\left(l^{*}\right)^{\alpha_{l}}}{\chi}\right)^{\frac{1}{1-\alpha_{x}}}[\chi-1] \psi^{*} / a_{j t}$, so $\pi_{j t}(i)=\pi / a_{j t}$ where $\pi=\left(\frac{\alpha_{x}\left(l^{*}\right)^{\alpha_{l}}}{\chi}\right)^{\frac{1}{1-\alpha_{x}}}[\chi-1] \psi^{*}$.

Proof of Lemma 3. First, note that in a constrained environment agents who do research will save all their income from their youth, as they are below the optimal R\&D investment and the R\&D cost function is strictly convex. Note that $H^{2}(0)=0$ and

$$
\begin{aligned}
H_{a}^{2}(a) & =F \tilde{\mu}_{j}^{\prime}\left(F_{k} a_{j, t-1}\right)+\frac{\left[1-\tilde{\mu}_{j}\left(F_{k} a_{j, t-1}\right)\right]}{g_{j}}-\frac{F_{k} \tilde{\mu}_{j}^{\prime}\left(F_{k} a_{j, t-1}\right)}{g_{j}} a_{j, t-1} \\
& =F_{k} \tilde{\mu}_{j}^{\prime}\left(F_{k} a_{j, t-1}\right)\left[1-\frac{1}{g_{j}} a_{j, t-1}\right]+\frac{\left[1-\tilde{\mu}_{j}\left(F_{k} a_{j, t-1}\right)\right]}{g_{j}}>0
\end{aligned}
$$

which is positive because $g>1$ and $a<1 .{ }^{28}$ Then, $H_{a}^{2}(0)=F_{k} \tilde{\mu}_{j}^{\prime}(0)+\frac{1}{g_{j}}$, which is positive and finite as $\lim _{a \rightarrow 0} \tilde{\mu}_{j}^{\prime}\left(F_{k} a_{j, t-1}\right)>0$.

For concavity of $H_{2}$ we need $H_{a a}^{2}<0$. Indeed,

$$
H_{a a}^{2}(a)=F_{k}^{2} \tilde{\mu}_{j}^{\prime \prime}\left(F_{k} a_{j, t-1}\right)\left[1-\frac{1}{g_{j}} a_{j, t-1}\right]-2 \frac{F_{k} \tilde{\mu}_{j}^{\prime}\left(F_{k} a_{j, t-1}\right)}{g_{j}}
$$

which is negative if $\left[1-\frac{1}{g_{j}} a_{j, t-1}\right]>0$. This holds as $g>1$ and $a^{*}<1$, so $a<1$. As for $H^{1}(a)$, note that, suppressing the subscript $j$,

$$
a_{t}^{\prime}=\left[\frac{\pi / a_{t}}{\kappa}-a_{t}^{\prime} \frac{\pi a_{t-1}}{\kappa a_{t}^{2}}\right] \tilde{\mu}^{\prime}\left[\frac{\pi a_{t-1} / a_{t}}{\kappa}\right]\left(1-\frac{1}{g} a_{t-1}\right)+\frac{\left[1-\tilde{\mu}\left[\frac{\pi a_{t-1} / a_{t}}{\kappa}\right]\right]}{g} .
$$

${ }^{28}$ Observe that $1-\frac{1}{g_{j}} a_{j, t-1}>0$ as $a_{j, t-1}<a_{j}^{*}$ and $\frac{1}{g_{j}} a_{j}^{*}=\frac{\mu_{j}^{*}}{g_{j}-1+\mu_{j}^{*}}<1$. 
where $a_{t}^{\prime} \equiv \frac{\partial a_{t}}{\partial a_{t-1}}$ so

$$
a_{t}^{\prime}=\frac{\frac{\pi / a_{t}}{\kappa} \tilde{\mu}^{\prime}\left[\frac{\pi a_{t-1} / a_{t}}{\kappa}\right]\left(1-\frac{1}{g_{j}} a_{j, t-1}\right)+\frac{\left[1-\tilde{\mu}\left[\frac{\pi a_{t-1} / a_{t}}{\kappa}\right]\right]}{g}}{1+\frac{\pi a_{t-1}}{\kappa a_{t}^{2}} \tilde{\mu}^{\prime}\left[\frac{\pi a_{t-1} / a_{t}}{\kappa}\right]}>0 .
$$

Setting $a_{t-1}=0, a^{\prime}=\frac{\pi / a_{t}}{\kappa} \tilde{\mu}^{\prime}(0)+\frac{1}{g}=\infty$. Note that $H^{1}\left(a_{t}\right)$ crosses the $45^{\circ}$ line at only one positive number. Using (22), setting $a_{t-1}=a_{t}$ yields a linear equation with one solution.

Proof of Proposition 2. Suppressing the time subscript, suppose spending on consumption is $s$. Across goods, demand is

$$
c_{i}=s\left(\frac{\xi_{i}}{q_{i}}\right)^{\varepsilon}\left[\sum_{j=1} \xi_{j}^{\varepsilon} q_{j}^{1-\varepsilon}\right]^{-1}
$$

Then

$$
\frac{c_{i}}{c_{j}}=\left(\frac{\xi_{i}}{\xi_{j}}\right)^{\varepsilon}\left(\frac{q_{j}}{q_{i}}\right)^{\varepsilon}
$$

so total expenditure is $s=\sum_{j=1} q_{j} c_{j}=q_{i} c_{i} \sum_{j=1}\left(\frac{\xi_{j}}{\xi_{i}}\right)^{\varepsilon}\left(\frac{q_{j}}{q_{i}}\right)^{1-\varepsilon}$ which implies

$$
c_{j}=s\left(\frac{\xi_{j}}{q_{j}}\right)^{\varepsilon}\left[\sum_{j=1} \xi_{j}^{\varepsilon} p_{j}^{1-\varepsilon}\right]^{-1}
$$

The static maximum is $\left(\sum_{j} \xi_{j} c_{j}^{\frac{\varepsilon-1}{\varepsilon}}\right)^{\frac{\varepsilon}{\varepsilon-1}}=c_{i}\left(\sum_{j} \xi_{j}\left(\frac{c_{j}}{c_{i}}\right)^{\frac{\varepsilon-1}{\varepsilon}}\right)^{\frac{\varepsilon}{\varepsilon-1}}$. Using (33) and (34),

$$
\left(\sum_{j} \xi_{j} c_{j}^{\frac{\varepsilon-1}{\varepsilon}}\right)^{\frac{\varepsilon}{\varepsilon-1}}=s\left(\sum_{j} \xi_{j}^{\varepsilon} q_{j}^{1-\varepsilon}\right)^{\frac{1}{\varepsilon-1}}
$$

Add this over all the agents regardless of income.

In equilibrium $\tilde{M}_{j t} y_{j t}=c_{j t}$ where $\tilde{M}_{j t}$ is the number of firms in industry $j$ that produces exactly the quantity of good $j$ not used to make intermediates, so combining (28) with (32) and suppressing $t$ we get $\tilde{M}_{j} l_{j} w_{t}=\alpha_{l} q_{j t} s\left(\frac{\xi_{i}}{q_{i}}\right)^{\varepsilon}\left[\sum_{j=1} \xi_{j}^{\varepsilon} q_{j}^{1-\varepsilon}\right]^{-1}$. Define $\Lambda_{t}^{j, j^{\prime}}$ as the share in nominal consumption of sector $j$ divided by that of sector $j^{\prime}$, so $\Lambda_{t}^{j, j^{\prime}}=\frac{q_{j t} c_{j t}}{q_{j^{\prime}} c_{j^{\prime} t}}$. Then,

$$
\frac{q_{j t}\left(\frac{\xi_{j}}{q_{j}}\right)^{\varepsilon}}{q_{j^{\prime} t}\left(\frac{\xi_{j^{\prime}}}{q_{j^{\prime}}}\right)^{\varepsilon}}=\frac{\tilde{M}_{j} l_{j}}{\tilde{M}_{j} l_{j^{\prime}}}=\frac{\tilde{M}_{j}}{\tilde{M}_{j}} \equiv \Lambda_{t}^{j, j^{\prime}}
$$


The expression $\Lambda_{t+1}^{j, j^{\prime}} / \Lambda_{t}^{j, j^{\prime}}$ then denotes the growth rate of industry $j$ relative to industry $j^{\prime}$, so $\frac{\Lambda_{t+1}^{j, j^{\prime}}}{\Lambda_{t}^{j, j^{\prime}}}=\left(\frac{q_{j t+1} / q_{j t}}{q_{j^{\prime} t+1} / q_{j^{\prime} t}}\right)^{1-\varepsilon}=\left(\frac{A_{j t+1} / A_{j t}}{A_{j^{\prime} t+1} / A_{j^{\prime} t}}\right)^{\varepsilon-1}$. This last step comes from the following. Define

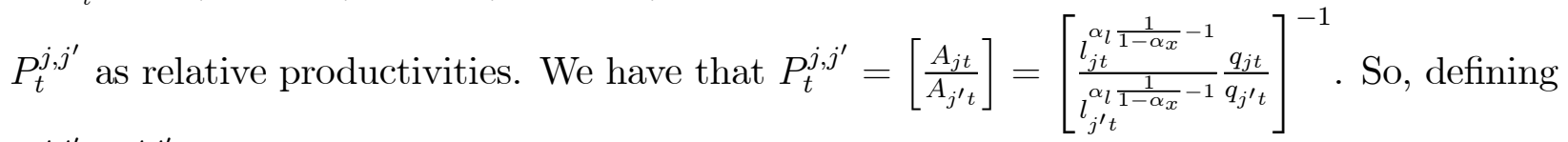
$P_{t+1}^{j, j^{\prime}} / P_{t}^{j, j^{\prime}}$ as the growth in the productivity gap between sectors $j$ and $j^{\prime}$, if $l_{j t}=l^{*} \forall j, t$ then $P_{t+1}^{j, j^{\prime}} / P_{t}^{j, j^{\prime}}=\left[\frac{q_{j t+1}}{q_{j^{\prime} t+1}}\right]^{-1} \div\left[\frac{q_{j t}}{q_{j^{\prime} t}}\right]^{-1}=\left(\frac{q_{j t+1} / q_{j t}}{q_{j^{\prime} t+1} / q_{j^{\prime} t}}\right)^{-1}$, which is negatively related to relative price changes. Writing prices in terms of the technology gap, $P_{t+1}^{j, j^{\prime}} / P_{t}^{j, j^{\prime}}=\left(\frac{A_{j t+1}}{A_{j^{\prime} t+1}} / \frac{A_{j t}}{A_{j^{\prime} t}}\right)=$ $\left(\frac{a_{j t+1}}{a_{j^{\prime} t+1}} / \frac{a_{j t}}{a_{j^{\prime} t}}\right) \times\left(\frac{g_{j}}{g_{j^{\prime}}}\right)$, so that $\frac{\Lambda_{t+1}^{j, j^{\prime}}}{\Lambda_{t}^{j, j^{\prime}}}=\left(\frac{a_{j t+1}}{a_{j^{\prime} t+1}} / \frac{a_{j t}}{a_{j^{\prime} t}}\right)^{\varepsilon-1} \times\left(\frac{g_{j}}{g_{j^{\prime}}}\right)^{\varepsilon-1}$. Finally, it follows from the definitions of $\Lambda_{t}^{j, j^{\prime}}$ and $G_{j t}$ that growth in relative shares $\Lambda_{t+1}^{j, j^{\prime}} / \Lambda_{t}^{j, j^{\prime}}$ equals relative industry growth rates $G_{j t} / G_{j^{\prime} t}$.

Proof of Proposition 1. Equation (33) gives the relative shares of consumption, and hence relative numbers of firms that produce final goods given a sequence for $q_{j t}$. Since $q_{j t}=\psi^{*} A_{j t}^{-1}$, the path of $q_{j t}$ is known at all dates given the path of $A_{j t}$. As shown earlier, any producer of final goods requires $\left(1+\left(1-\mu_{j t}\right) \chi\right) \frac{\alpha_{x}}{\chi}$ times its final output in units of good $j$ to produce intermediates $x_{j t}(i)$, which pins down the ratio of firms in a given industry $M_{j t}$ relative to those that produce goods for final use $\tilde{M}_{j t}$. Hence, since (33) tells us total final output for each good (relative to some benchmark), we know the number of firms in each industry down to a multiplicative factor, as in the working version of Samaniego (2010). To be precise, we have that $\left(\frac{A_{j t}}{A_{j^{\prime} t}}\right)^{\varepsilon} \frac{\left(1+\left(1-\mu_{j t}\right) \chi\right) \frac{\alpha_{x}}{\chi}}{\left(1+\left(1-\mu_{j^{\prime} t}\right) \chi \frac{\alpha_{x}}{\chi}\right.}=\frac{M_{j t}}{M_{j^{\prime} t}}$, and therefore, for all industries, we have for some constant $K_{t}$ that

$$
A_{j t}^{\varepsilon}\left(1+\left(1-\mu_{j t}\right) \chi\right) \frac{\alpha_{x}}{\chi} K_{t}=M_{j t}
$$

We must determine the factor $K_{t}$. In equilibrium, full use of the labor endowment of the economy implies that:

$$
2=N_{t}^{R}+\left(1+l^{*}\right) \sum_{j} M_{j t}+\sum_{j} M_{j t} \kappa_{j} n\left(\mu_{j t}\right) / a_{j, t-1}
$$

where $N_{t}^{R}$ is given by (21), and $M_{j t}$ is given by (37). Thus, (38) pins down $K_{t}$. Further, we require that the multiplicative constant that satisfies this equation also satisfies $N_{t}^{R}+M_{t} \leq 1$. Notice that, since $N_{t}^{R}=\sum_{j} M_{j t} \Pi_{j t}^{R}$, so we require $\sum_{j} M_{j t} \Pi_{j t}^{R}+M_{t} \leq 1$. Also, (38) becomes

$$
2=\sum_{j} M_{j t} \Pi_{j t}^{R}+\left(1+l^{*}\right) \sum_{j} M_{j t}+\sum_{j} M_{j t} \kappa_{j} n\left(\mu_{j t}\right) / a_{j, t-1}
$$


Since

$$
\Pi_{j t}^{R}=\rho \frac{(\chi-1) \alpha_{x}}{\left(1-\alpha_{l}-\alpha_{x}\right)} \mu_{j t} / a_{j t}-n_{j}\left(\mu_{j t}\right) / a_{j, t-1},
$$

(39) becomes $2=\sum_{j} M_{j t}\left[\rho \frac{(\chi-1) \alpha_{x}}{\left(1-\alpha_{l}-\alpha_{x}\right)} \mu_{j t} / a_{j t}\right]+\left(1+l^{*}\right) \sum_{j} M_{j t}$. Note that $l^{*}=\alpha_{l} /\left(1-\alpha_{l}-\alpha_{x}\right)$, $l^{*} \rightarrow \infty$ as $\alpha_{l} \rightarrow 1-\alpha_{x}$, and $M_{t}<2\left(1+l^{*}\right)^{-1}$. Thus, $M_{t}$ can be arbitrarily small for large enough $\alpha_{l}$, so that the requirement that $\sum_{j} M_{j t} \Pi_{j t}^{R}+M_{t} \leq 1$ is satisfied for $\alpha_{l}$ close enough to $1-\alpha_{x}$, given $F$ and initial conditions $a_{j 0}$.

Finally, we require $N_{t}^{R} \geq M_{t}$ in all periods. A sufficient condition would be $\min _{j} \Pi_{j t}^{R}>1$. Observe that research is more profitable for larger $a_{j, t-1}$ (the cost of R\&D drops). Moreover,

$$
\begin{aligned}
\Pi_{j t}^{R} & =\rho \frac{(\chi-1) \alpha_{x}}{\left(1-\alpha_{l}-\alpha_{x}\right)} \mu_{j t} / a_{j t}-n_{j}\left(\mu_{j t}\right) / a_{j, t-1} \\
& >\rho \frac{(\chi-1) \alpha_{x}}{\left(1-\alpha_{l}-\alpha_{x}\right)} \mu_{j t} / a_{j}^{*}-n_{j}\left(\mu_{j t}\right) / a_{j, t-1}
\end{aligned}
$$

There are 2 cases. First suppose the industry is in Region 1 or 2 . If (41) is satisfied for $a_{j 0}$, and if $a_{j t}$ is increasing over time (i.e. for industries in Regions 1 and 2) then the result holds. Note that $\pi=\rho\left(1-\frac{1}{\chi}\right) \frac{\alpha_{x}}{\left(1-\alpha_{l}-\alpha_{x}\right)}$ : hence, as $\alpha_{l} \rightarrow 1-\alpha_{x}, \pi \rightarrow \infty$. Also, note from (40) that $\Pi_{j t}^{R}$ is strictly increasing in $\pi$ for any $\mu$, so $\Pi_{j t}^{R}$ is increasing and unbounded regardless of whether or not the industry is constrained. Thus, $\min _{j} \Pi_{j t}^{R}>1$ is satisfied as long as $\alpha_{l}$ is sufficiently close to $1-\alpha_{x}$, and the industry is not in Region 3 .

In Region 3, $\Pi_{j t}^{R}=\rho \frac{(\chi-1) \alpha_{x}}{\left(1-\alpha_{l}-\alpha_{x}\right)} \tilde{\mu}_{j}\left(F S a_{j, t-1}\right) / a_{j t}-F S$, and both $a$ and $\mu_{j t}$ drop over time. What happens to $\Pi_{j t}^{R}$ ? $\lim _{a_{j, t-1} \rightarrow 0} \tilde{\mu}_{j}\left(F S a_{j, t-1}\right) / H_{j}^{2}\left(a_{j, t-1}\right)=\frac{\mu_{j t}^{\prime}(0)}{F_{k} \tilde{\mu}_{j}^{\prime}(0)\left[1-\frac{1}{g_{j}} a_{j, t-1}\right]+\frac{\left[1-\tilde{\mu}_{j}(0)\right]}{g_{j}}}>$ 0The profit from research converges to a positive limit. As before, we can guarantee that both initially and in the limit $\Pi_{j t}^{R}>0$ provided $\alpha_{l}$ is sufficiently close to $1-\alpha_{x}$.

That the economy converges to a balanced growth path follows from the fact that $\mu_{j t}$ converges to a constant in each industry. Proposition 2 then implies (see Ngai and Pissarides (2007)) that, as $t \rightarrow \infty$, there is one industry with a nominal share that converges to unity - which is $\arg \max _{j}\left\{\lim _{t \rightarrow \infty} \frac{a_{j, t+1}}{a_{j t}} g_{j}\right\}$ if $\varepsilon>1$ and $\arg \min _{j}\left\{\lim _{t \rightarrow \infty} \frac{a_{j, t+1}}{a_{j t}} g_{j}\right\}$ if $\varepsilon<1$.

Proof of Propositions 3 and 4. Results follow from the analysis of Regions $1-3$.

Proof of Proposition 5. Preliminary derivations. Note that if $\tilde{n}_{j}(\mu)=\kappa_{j} n(\mu)$, then $\tilde{\mu}(x)=n^{-1}\left(\frac{x}{\kappa_{j}}\right)$, so $\tilde{\mu}^{\prime}(x)=\left.\frac{1}{\kappa_{j}} \frac{d n^{-1}(a)}{d x}\right|_{a=x / \kappa_{j}}=\frac{1}{\kappa_{j}}\left[\frac{d n(\mu)}{d x}\right]^{-1}$, and $\tilde{\mu}^{\prime \prime}(x)=\left.\left(\frac{1}{\kappa_{j}}\right)^{2} \frac{d^{2} n^{-1}(a)}{d x^{2}}\right|_{a=x / \kappa_{j}}$ $<0$. If $F$ implies the industry is in Region 1, then the derivative is zero. Hence, suppose that $F$ puts the industry in Regions 2 or 3 . Note $\gamma_{j t}=\tilde{\mu}_{j}\left(F_{k} a_{j, t-1}\right)\left[\frac{1}{a_{j, t-1}}-\frac{1}{g_{j}}\right]+\frac{1}{g_{j}}$, so

$$
\gamma_{F}=(1+r) a_{j, t-1} \tilde{\mu}_{j}^{\prime}\left(F_{k} a_{j, t-1}\right)\left[\frac{1}{a_{j, t-1}}-\frac{1}{g_{j}}\right] \text {. }
$$


Differentiating (42) with respect to $\kappa$ yields $\frac{\partial^{2} \gamma_{j k}}{\partial F_{k} \partial \kappa_{j}}=Q_{1}+Q_{2}$, where $Q_{1}=(1+r) a_{j} \frac{d \tilde{\mu}_{j}^{\prime}\left(F_{k} a_{j}\right)}{d \kappa}\left[\frac{1}{a_{j}}-\frac{1}{g_{j}}\right]$ $<0$ and $Q_{2}=\frac{\partial g_{j}}{\partial \kappa_{j}}(1+r) a_{j} \tilde{\mu}^{\prime}\left[F_{k} a_{j}\right] \frac{1}{g_{j}^{2}}<0$. To verify that $\frac{d \tilde{\mu}_{j}^{\prime}(x)}{d \kappa}<0, \tilde{\mu}_{j}(x)=\tilde{\mu}\left(\frac{x}{\kappa}\right)$, observe that $\tilde{\mu}_{j}^{\prime}(x)=\frac{1}{\kappa} \tilde{\mu}^{\prime}\left(\frac{x}{\kappa}\right)$ and $\frac{d \tilde{\mu}_{j}^{\prime}(x)}{d \kappa}=-\frac{1}{\kappa^{2}} \tilde{\mu}^{\prime}\left(\frac{x}{\kappa}\right)+\frac{1}{\kappa} \tilde{\mu}^{\prime \prime}\left(\frac{x}{\kappa}\right)<0$.

\section{B Taylor Decomposition}

Recall that $a_{j t}=H_{j}\left(a_{j, t-1}\right)$, where $H_{j}\left(a_{j, t-1}\right)=\min \left\{H_{j}^{1}\left(a_{j, t-1}\right), H_{j}^{2}\left(a_{j, t-1}\right)\right\}$. Then, $\gamma_{j k}=$ $H_{j}\left(a_{j, t-1}\right) / a_{j, t-1}=\frac{\mu_{j t}}{a_{j, t-1}}+\frac{\left[1-\mu_{j t}\right]}{g_{j}}$. Since $H_{j}$ is a kinked function, define $\hat{\mu}_{j}($.$) as a smooth$ approximation to $\mu_{j t}$. $\hat{\mu}_{j}(F a)$ is twice-differentiable and strictly increasing up to the value of $F$ in the benchmark country. Also, $\hat{\mu}_{j}^{\prime}(F a)=0$ for higher values of $F$, but $\left\|\hat{\mu}_{j}(F a)-\mu_{j t}\right\|<$ $\epsilon$ for some small $\epsilon>0 .{ }^{29}$ Then let $\Gamma(F, \kappa, a)=\frac{\hat{\mu}_{j}(F a)}{a_{j, t-1}}+\frac{\left[1-\hat{\mu}_{j}(F a)\right]}{g_{j}}$, so that $\Gamma$ is a smooth approximation to $\gamma$. We take a second order Taylor approximation of the function $\Gamma$ around some industry with $\kappa_{j}=\kappa^{*}, A_{j}=A^{*}$, evaluated at some level of financial development $F^{*}$ and initial conditions $a^{*}$ :

$$
\begin{aligned}
\Gamma(F, \kappa, a) \simeq & \Gamma\left(F^{*}, \kappa^{*}, a^{*}\right)+\Gamma_{a}\left(F^{*}, \kappa^{*}, a^{*}\right)\left(a-a^{*}\right) \\
& +\Gamma_{F}\left(F^{*}, \kappa^{*}, a^{*}\right)\left(F-F^{*}\right)+\Gamma_{\kappa}\left(F^{*}, \kappa^{*}, a^{*}\right)\left(\kappa-\kappa^{*}\right) \\
& +\frac{1}{2} \Gamma_{a a}\left(F^{*}, \kappa^{*}, a^{*}\right)\left(a-a^{*}\right)^{2}+\frac{1}{2} \Gamma_{F F}\left(F^{*}, \kappa^{*}, a^{*}\right)\left(F-F^{*}\right)^{2} \\
& +\frac{1}{2} \Gamma_{\kappa \kappa}\left(F^{*}, \kappa^{*}, a^{*}\right)\left(\kappa-\kappa^{*}\right)^{2}+\frac{1}{2} \Gamma_{\kappa \kappa}\left(F^{*}, \kappa^{*}, a^{*}\right)\left(\kappa-\kappa^{*}\right)^{2} \\
& +\Gamma_{a F}\left(F^{*}, \kappa^{*}, a^{*}\right)\left(a-a^{*}\right)\left(F-F^{*}\right) \\
& +\Gamma_{a \kappa}\left(F^{*}, \kappa^{*}, a^{*}\right)\left(a-a^{*}\right)\left(\kappa-\kappa^{*}\right) \\
& +\Gamma_{F \kappa}\left(F^{*}, \kappa^{*}, a^{*}\right)\left(F-F^{*}\right)\left(\kappa-\kappa^{*}\right)
\end{aligned}
$$

where $\Gamma_{x}$ equals the derivative of $\Gamma$ with respect to $x$ and $\Gamma_{x y}$ equals the derivative of $\Gamma$ with respect to $x$ and $y$. This reduces to:

$$
\begin{aligned}
\Gamma(F, \kappa, a)= & B_{j}+B_{k}+\beta_{a} a_{j k}+\beta_{a^{2}} a_{j k}^{2}+\beta_{a \kappa} a_{j k} \kappa_{j} \\
& +\beta_{F a} F_{k} a_{j k}+\beta_{F \kappa} F_{k} \kappa_{j}+\epsilon_{j k}
\end{aligned}
$$

as all terms except those involving interactions and the initial conditions $a_{j k}$ are country- or industry-specific and will be soaked up by industry and country indicator variables $\left(B_{j}\right.$ and

${ }^{29}$ AHM suggest this approach to handling kinks. We interpret it as the outcome in a similar model in which there is a little heterogeneity, or a little randomness in the funds that firms receive. 
$\left.B_{k}\right)$. The remaining terms are interaction terms, multiplied by their cross-derivatives.

Now, recall that research intensity is some function of $\kappa$, so $\kappa=f(R N D)$ where $f^{\prime}<0$ over the range of interest. Then, again using a Taylor approximation,

$$
\kappa_{j} \simeq f\left(R N D^{*}\right)-f^{\prime}\left(R N D^{*}\right) R N D^{*}+f^{\prime}\left(R N D^{*}\right) R N D_{j}
$$

where $R N D^{*}=f^{-1}\left(\kappa^{*}\right)$. Using equation (44) to replace $\kappa_{j}$ with $R N D_{j}$ yields an equation of the same form as (43) except that all the interaction terms involving $\kappa_{j}$ become interaction terms involving $R N D_{j}$, and these terms have the opposite sign of the interaction terms involving $\kappa_{j}$ :

$$
\begin{aligned}
\Gamma(F, \kappa, a)= & \beta_{j}+\beta_{k}+\beta_{a} a_{j k}+\beta_{a^{2}} a_{j k}^{2}+\beta_{a, R N D} a_{j k} R N D_{j} \\
& +\beta_{F a} F_{k} a_{j k}+\beta_{F, R N D} F_{k} R N D_{j}+\epsilon_{j k}
\end{aligned}
$$

Noting that $\log \gamma \simeq \gamma-1$, replacing the expression for $\log \gamma$ in equation (15) with (45) yields equation (16).

Observe that the share of industry $j$ in the manufacturing sector of country $k$ is a possible empirical proxy of $a_{j k}$ Let $m_{k}$ be manufacturing GDP in country $k$, and let $q_{j k} \bar{c}_{j k}$ be value added in industry $j$ in country $k$, so $s_{j k}=q_{j k} \bar{c}_{j k} / m_{k}$ is the share of $j$ in the manufacturing sector of country $k$. Define $\Lambda_{t}^{j, j^{\prime}}$ as the share in nominal consumption of sector $j$ divided by that of a benchmark sector $j^{\prime}: \Lambda_{t}^{j, j^{\prime}}=\frac{q_{j k} \bar{c}_{j k}}{q_{j^{\prime} k} \bar{c}_{j^{\prime} k}}$. Let $L_{k, k^{\prime}}^{j}$ be $\frac{\Lambda_{k}^{j, j^{\prime}}}{\Lambda_{k^{\prime}}^{j, j^{\prime}}}$, the share of $j$ relative to $j^{\prime}$ in country $k$ relative to a benchmark country $k^{\prime}$. If the benchmark good is more expensive in $k$ than $k^{\prime}$ by a factor $\phi_{k}$, then

$$
L_{k, k^{\prime}}^{j}=\frac{1}{\phi_{k}^{1-\varepsilon}} \frac{q_{j k}^{1-\varepsilon}}{q_{j k^{\prime}}^{1-\varepsilon}}=\frac{1}{\phi_{k}^{1-\varepsilon}} \frac{a_{j k}^{\varepsilon-1}}{a_{j k^{\prime}}^{\varepsilon-1}} .
$$

Taking logs yields a country constant, $(\varepsilon-1) \log \phi_{k}$, an industry constant $-(\varepsilon-1) \log a_{j k^{\prime}}$, and a constant times the share of industry $j$ in the manufacturing sector of country $k$, $(\varepsilon-1) \log a_{j k}$. Thus

$$
\begin{aligned}
\log a_{j k} & =\log \left(s_{j k}\right)-\log \left(s_{j^{\prime} k}\right)-\Lambda_{k^{\prime}}^{j, j^{\prime}}+(\varepsilon-1) \log a_{j k^{\prime}}-(\varepsilon-1) \log \phi_{k} \\
& =\log \left(s_{j k}\right)+z_{j}^{1}+z_{k}^{2}
\end{aligned}
$$

where $z_{j}^{1}$ and $z_{k}^{2}$ are industry and country-specific constants, respectively. Finally, noting that for $|x|<1$ we have that $\log (x+1) \approx x$ as long as $|x|$ is sufficiently small, and since $a_{j k}<1$ and $s_{j k}<1$, we have that $\log a_{j k} \approx\left(a_{j k}-1\right)$ and $\log \left(s_{j k}\right) \approx\left(s_{j k}-1\right)$, so (47) 
becomes an equation of the form $a_{j k} \approx s_{j k}+z_{j}^{1}+z_{k}^{2}$. The constant terms will be absorbed by country and industry dummies, leaving the industry share $s_{j k}$ as a proxy for initial $a_{j k}$.

\section{Calibration procedure}

To match the parameters $\kappa_{j}, \sigma$ and $F_{k}$, we proceed as follows.

First, to make sure we have a measure of $g_{j}$ that is closely related to R\&D intensity as in the model, we regress R\&D intensity on productivity growth rates from Jorgenson et al (2007). ${ }^{30}$ We set $g_{j}$ to match the predicted TFP numbers. We use predicted rather than actual TFP numbers to reflect the TFP-R\&D link in the model, otherwise the model could not match both TFP and \&D numbers at once. Still, the correlation between the actual (rather than predicted) TFP values and R\&D is 0.39 , significant at the 1 percent level.

Then, we assume a value of $\sigma$. Given $\sigma$, the spillover equation (13) then predicts a success rate $\mu_{j}^{*}$ that corresponds to $g_{j}$. The first order condition of the researcher's problem in an unconstrained environment (10) then yields values of $\kappa_{j}$. We use this to compute $a_{j}^{*}$ using equation (15), and use all these parameters to construct industry R\&D intensity values in the model economy. Then, we use the sum of squared deviations between R\&D intensity in the model and the data to generate a new guess for $\sigma$, iterating until we converge to a minimum. This is essentially a method of moments procedure that selects values for both $\sigma$ and $\kappa_{j}$ by matching industry R\&D intensity and productivity growth rates from the data.

To generate industry growth rates we also need initial conditions $a_{j k}$ for each countryindustry pair. Using the condition for optimal allocation of spending across industries, the share of industry $i$ relative to industry $j$ in country $k$ relative to another country $k^{\prime}$ is a function only of $\varepsilon$ and of the relative values of $\frac{a_{i k}}{a_{j k}}$ in the two countries, and a countryspecific constant - see equation (46). There, an assumption regarding the relative price of a benchmark good in country $k$ is used to link industry shares to initial conditions. Recall that all prices in all countries are expressed relative to the wage: thus, a higher price for benchmark good $j^{\prime}$ in one country implies lower labor productivity in that industry. Then using (46) we can use industry shares to derive the values of $a_{j k}$ in all other industries in all countries, provided we know the productivity gap of some benchmark industry $j$ in each country. This amounts to a choice of the constant $\phi_{k}$ in equation (46).

We proceed as follows. First, we choose our benchmark industry. We select Textiles (ISIC 321), because data for this industry are available for all countries, and because it is a relatively non-R\&D intensive industry. Then, for each country, we select values of $a_{\text {textiles, } k}$

\footnotetext{
${ }^{30}$ In some cases, the industry classification in Jorgenson is a little more aggregated, than INDSTAT3, e.g. Food and Beverages are not separate. In these cases, we use the same productivity growth rate for both.
} 
so as to satisfy two assumptions:

1. $a_{j k} \leq a_{j}^{*}$ in all industries $j$ and countries $k$;

2. $a_{\text {textiles }, k}$ is a linear, non-decreasing function of financial development.

We begin by assuming that $a_{\text {textiles }, k}$ is equal in all countries, and select $a_{\text {textiles }, k}$ so that values of $a_{j k}$ for all other $j, k$ are as high as then can be while satisfying the restriction that $a_{j k} \leq a_{j}^{*}$. Given this assumption, ${ }^{31}$ we can obtain all the required initial conditions and can generate pseudo-data from the model. Then, we repeat our experiments, assuming that $a_{\text {textiles }, k}$ is a linear function of financial development. We explore different values of the slope of this function, ranging from 0 ( $a_{\text {textiles }, k}$ is equal in all countries) to the highest slope such that $a_{\text {textiles }, k}$ in the least financially developed economy is zero. ${ }^{32}$

Thus, given data on industry shares and an assumption on relative price differences (or, equivalently, productivity differences), we can compute the entire matrix of $a_{j k}$ values.

An issue is that, due to data availability, there are only 1084 data points, whereas there are 1148 industry-country pairs in principle. This is not a concern in that, for our regressions with pseudo-data, we simply focus on the same 1084 country-industry pairs reported in the data. However, it does matter for constructing total R\&D intensity in each country in the model. For these purposes, we simply assume that the shares of the missing industries are zero (in any case, the missing industries constitute a small fraction of the manufacturing sectors of these countries, with the exception of Belgium and Morocco).

The only remaining parameters to calibrate are the borrowing constraints, $F_{k}$. We select these parameters as follows. Given a choice of $F_{k}$, the model generates industry R\&D intensity values. We use the share of each industry to predict $R \& D$ intensity in the manufacturing sector of each country in the model. We compare these numbers to the data, and select $F_{k}$ so as to match R\&D intensity in each country.

\footnotetext{
${ }^{31}$ Since the interaction of finance and $\mathrm{R} \& \mathrm{D}$ is weaker when $a_{j k}$ is higher, this is a conservative assumption.

${ }^{32}$ Notice that this procedure allows the calibration of $a_{j k}$ and of industry growth without requiring values of $\xi_{j}$. This is because comparisons of relative industry shares across countries do not depend on $\xi_{j}$. These are the comparisons that we use to calibrate $a_{j k}$, assuming given values of $a_{\text {textiles, } k}$, which we obtain through auxiliary assumptions on $\phi_{k}$, which are also unrelated to $\xi_{j}$.
} 


\title{
Structural Change and Financing Constraints: Technical Appendix
}

\author{
Anna O. Ilyina and Roberto M. Samaniego*
}

February 26, 2011

\begin{abstract}
In this Appendix we provide additional quantitative results. The calibrated model generates "stages of diversification" for several countries, using initial conditions based on actual data. We estimate the full regression specification suggested by the model and find that the additional terms are generally not statistically significant, while the terms of interest are robust to the generalized specification. We also discuss extensions of the basic model, e.g. with multiple limiting industries.
\end{abstract}

JEL Codes: G18, O14, O16, O33, O47.

Keywords : Financial development, industry growth, R\&D intensity, external finance dependence, convergence dynamics, structural change, stages of diversification.

\section{Introduction}

In this appendix, we check some of the basic empirical predictions and foundations of the model economy. We estimate equation (16), which is similar to Rajan and Zingales (1998) and Ilyina and Samaniego (forthcoming) except for some additional second-order terms. We also see whether the model can generate the "stages of diversification" pattern of structural change for realistic parameterizations, with a large number of industries. Finally, we study the aggregate behavior of the model economy. With a fully calibrated model economy, we can determine which industry-country pairs lie in Regions 1, 2 or 3 and, consequently, determine

${ }^{*}$ This paper should not be reported as representing the views of the IMF. The views expressed are those of the author(s) and do not necessarily represent those of the IMF or IMF policy. Anna Ilyina: International Monetary Fund, 700 19th St NW, Washington, DC 20431. Roberto Samaniego: Department of Economics, George Washington University, 2115 G St NW Suite 340, Washington, DC 20052. Tel: (202) 994-6153. Fax: (202) 994-6147. E-mail: roberto@gwu.edu. 
which countries might lie in a development trap or a development sink, as defined by the model. In addition, we see whether the calibrated multi-sector model fits the empirical specification predicted by the one-sector model of AHM.

For the "preferred parameterization" that maximizes the R\&D-financial development interaction coefficient, we find that financing constraints are indeed positively related to economic growth rates in the model, and that the model suggests that all countries should converge in terms of GDP growth rates, although not necessarily in income levels.

In $I I$ we provide empirical support for some of the basic predictions and assumptions of the model, such as the link between research intensity and external finance dependence, between research intensity and the inability to raise external funds, and so on. In $I I I$ we estimate the full specification suggested by the model using country and industry data drawn from INDSTAT3 as well as other sources. In section $I V$ we discuss some extensions of the model, including the economy with multiple limiting industries, and equilibria in which $N_{t}^{E}>N_{t}^{R}$. In $V$ we discuss the ability of the model to generate "stages of diversification", and in $V I$ we discuss some implications of the model for aggregate growth.

\section{Empirical validity of model assumptions}

We wish to verify that certain assumptions and predictions of the model are empirically valid:

1. the prediction that $R \& D$ spending at the national level is positively correlated with the use of external finance, comparing across countries.

2. the assumption that $R \& D$ intensity in the benchmark economy is positively related to the need for external finance, comparing across industries.

3. the assumption that $\mathrm{R} \& \mathrm{D}$ intensity is negatively related to measures of the ability to raise external funds.

4. the prediction that $\mathrm{R} \& \mathrm{D}$ intensity is positively related to the rate of industry growth in the benchmark economy, comparing across industries.

5. the prediction that R\&D intensity and industry growth are positively related to productivity growth in the benchmark economy, comparing across industries.

6. the assumption that $\varepsilon<1$. We also provide estimates of $\varepsilon$, and use them to aid in the interpretation of related empirical work. 
Country measures are constructed for the 41 countries in the RZ and Ilyina and Samaniego (forthcoming) sample. We measure country R\&D intensity using the 2005 R\&D to GDP ratio as reported in the World Development Indicators 2007 of the World Bank. We measure country financial development using the credit-to-GDP ratio, averaged over the 1990s as computed in Ilyina and Samaniego (forthcoming). We measure financial development earlier to avoid simultaneity concerns.

Industry measures are constructed for the 28 manufacturing industries in the United Nations INDSTAT3 database, which is used to construct measures of industry growth in the related literature. However, for certain measures we are able to disaggregate further, as discussed below.

We seek measures of financing and research activity that are not themselves affected by financing constraints. Where possible, we use data on publicly traded US firms, following the argument in RZ that (in normal times) these firms have access to highly liquid capital markets so that the median firm in a given industry in Compustat is not constrained.

We measure the observed need for external finance $E F D_{j}$ using the share of expenditures that is not financed by cash flow from operations. As in RZ, cash flow from operations is defined as cash flow from operations plus changes in payables minus changes in receivables plus changes in inventories, and is computed using DATA 110 and DATA 2, 3 and 70 (or DATA 302, 303 and 304 if 2, 3, 70 are unavailable). Expenditures and cash flow are summed up over the relevant decade (the 1990s) to compute the firm-level measures, and the median firm value is used as an index of industry level financing need $E F D_{j}$.

Research intensity $\left(R N D_{j}\right)$ is defined as R\&D expenditures (DATA 46 in Compustat) divided by total expenditures (defined as DATA 128). The industry measure of RND is the median firm value. See Ilyina and Samaniego (forthcoming).

We measure "benchmark" industry growth using the growth rate in sales at the median firm in each industry in Compustat (DATA 12), following Fisman and Love (2007) $\left(G R_{j}\right)$. We also use the industry fixed effect in a regression of industry growth on country and industry dummies $\beta_{j}$, as suggested by equation (15).

Since the model predicts that productivity growth and industry growth are positively related in the benchmark economy, we check this prediction using measures of these two variables from Jorgenson et al (2007). They report industry (value-added) growth and total factor productivity growth in 76 private industries in the United States over the period 1960-2004, including industries from both manufacturing and non-manufacturing.

A premise of our paper is that $R \& D$ intensive projects have significantly greater difficulty raising funds. As a result, we examine the following two indicators of the industry-specific ability to raise external funds, again using publicly traded firms in the United States. 
- Better collateralizability of a firm's assets tends to improve its ability to raise external funds in a less financially developed economy, see Kiyotaki and Moore (1997). This suggests that one proxy for the ease of external financing might be "asset fixity" $\left(F I X_{j}\right)$. We measure $F I X_{j}$ as a ratio of fixed assets to total assets in Compustat (DATA 8 divided by DATA 6), following Braun and Larraín (2005). FIX $X_{j}$ at the industry level is the median firm value.

- Greater asymmetric information, on the other hand, may hinder the ability of firms to raise external funds. Barron, Kim, Lim and Stevens (1998) and Thomas (2002) suggest that variability in earnings forecasts may indicate more heterogeneity of information across analysts concerning future profitability of a particular firm $\left(A S Y M_{j}\right)$. Hence, we take $A S Y M_{j}$ to be a measure of difficulty raising funds. Corporate earnings forecasts are available from the Institutional Brokers' Estimate System (IBES). We use longterm ("3 - 5 years ahead") forecasts because the return to a current research project is not likely to materialize in the near term. Again, we average the measure for each firm over the 1990s and take the median firm value to be the industry-level measure of $A S Y M_{j}$.

Again, we wish to verify that certain assumptions of the model are empirically valid. These include the fact that R\&D intensity in the benchmark economy is positively related to the need for external finance, and the fact that R\&D intensity is positively related to the rate of industry growth in the benchmark economy. In addition, we explore whether or not R\&D intensity is related to measures of the ability to raise external funds. This is because the model assumes that it is more difficult to raise financing for $\mathrm{R} \& \mathrm{D}$ projects compared to other types of projects.

The results are as follows.

1. R\&D and financing constraints: First of all, the model builds on a link between financing constraints and R\&D spending. Sure enough, among the countries in the Ilyina and Samaniego (forthcoming) sample, the cross-country correlation between R\&D as a share of GDP and financial development as measured using the credit-to-GDP ratio is positive and high. See Figure $A 1$. 


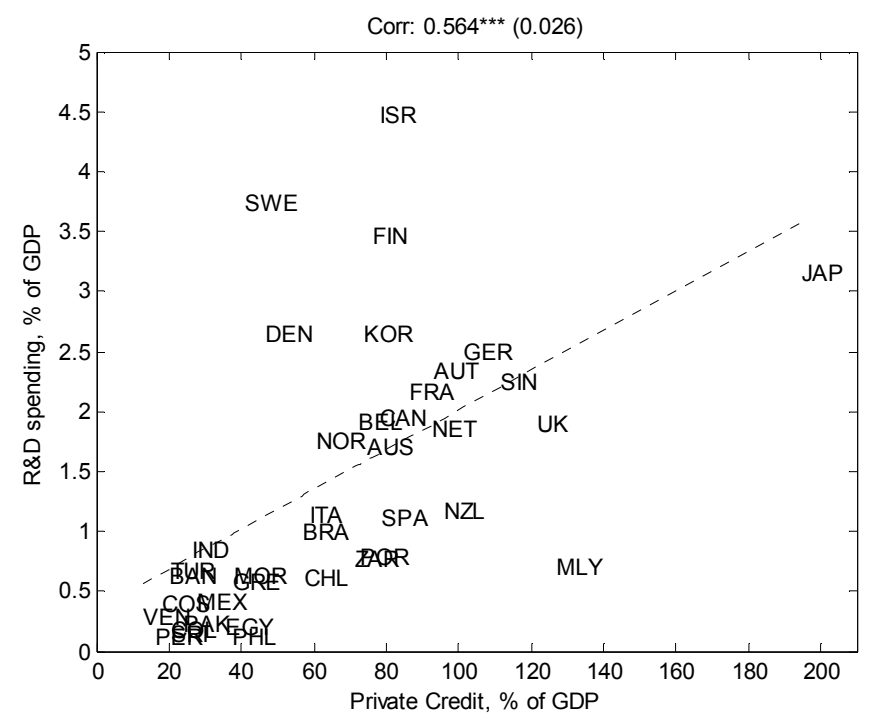

Figure $A 1-\mathrm{R} \& \mathrm{D}$ spending and financial development. R\&D spending is the R\&D to GDP ratio, 2002. Financial development is measured using the credit-to-GDP ratio, averaged over the 1990s. Sources - World Bank (2007) and Ilyina and Samaniego (forthcoming). Excluding Japan, the correlation is 0.526 and still highly significant.

2. R\&D and the need for external funds: The cross-industry correlation between $R N D_{j}$ and $E F D_{j}$ is positive and high. Moreover, this is true not just at the industry level but also at the firm level. See Tables $A 1$ and $A 2$. Ilyina and Samaniego (forthcoming) find the the positive cross-industry correlation between $R N D_{j}$ and $E F D_{j}$ is stable across decades and, moreover, that there is no other technological characteristic that is as robustly related to $E F D_{j}$. This finding is what underpins the structure of the model.

3. $R \& D$ and the ability to raise external funds: Measures of ability are negatively linked to $R N D_{j}$. At the firm level, the measure $F I X_{j}$ is strongly negatively correlated ${ }^{1}$ with $R N D_{j}$, whereas $A S Y M_{j}$ is positively correlated with $R N D_{j}$. At the industry level, the same is the case except that $A S Y M_{j}$ is not significantly related to $R N D_{j}$. The results concerning $F I X_{j}$ are perhaps not surprising, but those concerning $A S Y M_{j}$ are striking, particularly considering that there is a presumption in the literature that forecasters are likely to herd

\footnotetext{
${ }^{1}$ We also measure fixity in two other ways. We excluded cash and recievables from the definition of "total assets", as these are arguably not productive assets per se. We also computed $F I X_{j}$ using only firms that do not conduct $\mathrm{R} \& \mathrm{D}$, as what we are interested in is the ability of the firm to raise funds for research through its non R\&D-assets. All measures of $F I X_{j}$ were highly correlated amongst themselves, and results were broadly similar.
} 
towards the consensus forecast, which would suggest that we should observe little if any link between $A S Y M_{j}$ and other firm characteristics.

4. R\&D and industry growth: The model assumes that R\&D intensity is positively related to industry growth in the benchmark country, and we find that this is also the case in the data. See Tables 1 and 2. For productivity growth differences to map into industry growth differences in the model economy requires that $\varepsilon>1$ among the industries in question. One way for us to assess this is using equation (15). If $\varepsilon>1$, equation (15) implies that the industry fixed effect $\beta_{j}$ in a country-industry growth regression should be positively related to growth in industry $j$ in the benchmark country $G R_{j}$. Table $A 2$ shows that the data support the prediction that $\beta_{j}$ and $G R_{j}$ are related across manufacturing industries.

\section{Table A1 -- Regression of financial variables on RND at the firm level}

This table shows the results of regressing external finance dependence (D), asset fixity (FIX) and asymmetric information (ASYM) on R\&D intensity (RND) at the firm level. Results are reported without industry fixed effects, with industry fixed effects, and with industry fixed effects for Manufacturing and Non-manufacturing firms separately. Results are reported for the 1990s. All variables are normalized by their means and standard deviations, so coefficients can be interpreted as correlations. Standard errors are in parentheses. One, two and three asterisks represent statistical significance at the 10,5 and 1 percent levels respectively.

\begin{tabular}{|c|c|c|c|c|c|c|}
\hline & 1 & 2 & 3 & 4 & 5 & 6 \\
\hline$D(j)$ & $\begin{array}{l}\mathbf{0 . 3 1 4} * * * \\
(0.033)\end{array}$ & & - & $\begin{array}{l}\mathbf{0 . 2 1 8 * * *} \\
(0.027)\end{array}$ & $\begin{array}{l}\mathbf{0 . 2 4 3} * * * * \\
(0.035)\end{array}$ & $\begin{array}{l}\mathbf{0 . 1 9 4 * * *} \\
(0.029)\end{array}$ \\
\hline FIX(j) & - & $\begin{array}{l}-\mathbf{- 0 . 5 9 9} * * * \\
(0.028)\end{array}$ & - & $\begin{array}{l}-\mathbf{0 . 5 6 2} * * * \\
(0.027)\end{array}$ & - & $\begin{array}{l}-\mathbf{0 . 5 4 8} * * * \\
(0.028)\end{array}$ \\
\hline $\operatorname{ASYM}(\mathrm{j})$ & - & & $\begin{array}{l}\mathbf{0 . 2 8 1} * * * \\
(0.033)\end{array}$ & - & $\begin{array}{l}\mathbf{0 . 1 9 1 * * *} \\
(0.035)\end{array}$ & $\begin{array}{l}\mathbf{0 . 0 7 0} * * * \\
(0.029)\end{array}$ \\
\hline Obs & 893 & 893 & 893 & 893 & 893 & 893 \\
\hline $\mathrm{R}^{2}$ & 0.099 & 0.359 & 0.079 & 0.405 & 0.130 & 0.409 \\
\hline
\end{tabular}

5. R\&D, industry growth and productivity growth: Equation (15) indicates that, in the benchmark economy, industry value added growth rates and productivity growth rates should be positively correlated in the benchmark economy, provided that $\varepsilon>1$. Jorgenson 
et al (2007) report industry value-added growth and productivity growth rates for the United States (1960-2004). The correlation between these two variables is 0.84 in the full sample of 76 industries; within manufacturing it is 0.97 , and within services and other industries it is 0.35. All values are positive and significant at the 5 percent level or better (Spearman rank correlations, which are less sensitive to outliers, are also positive and significant). See Figure $A 2$.

Table A2 -- Correlations between different industry measures

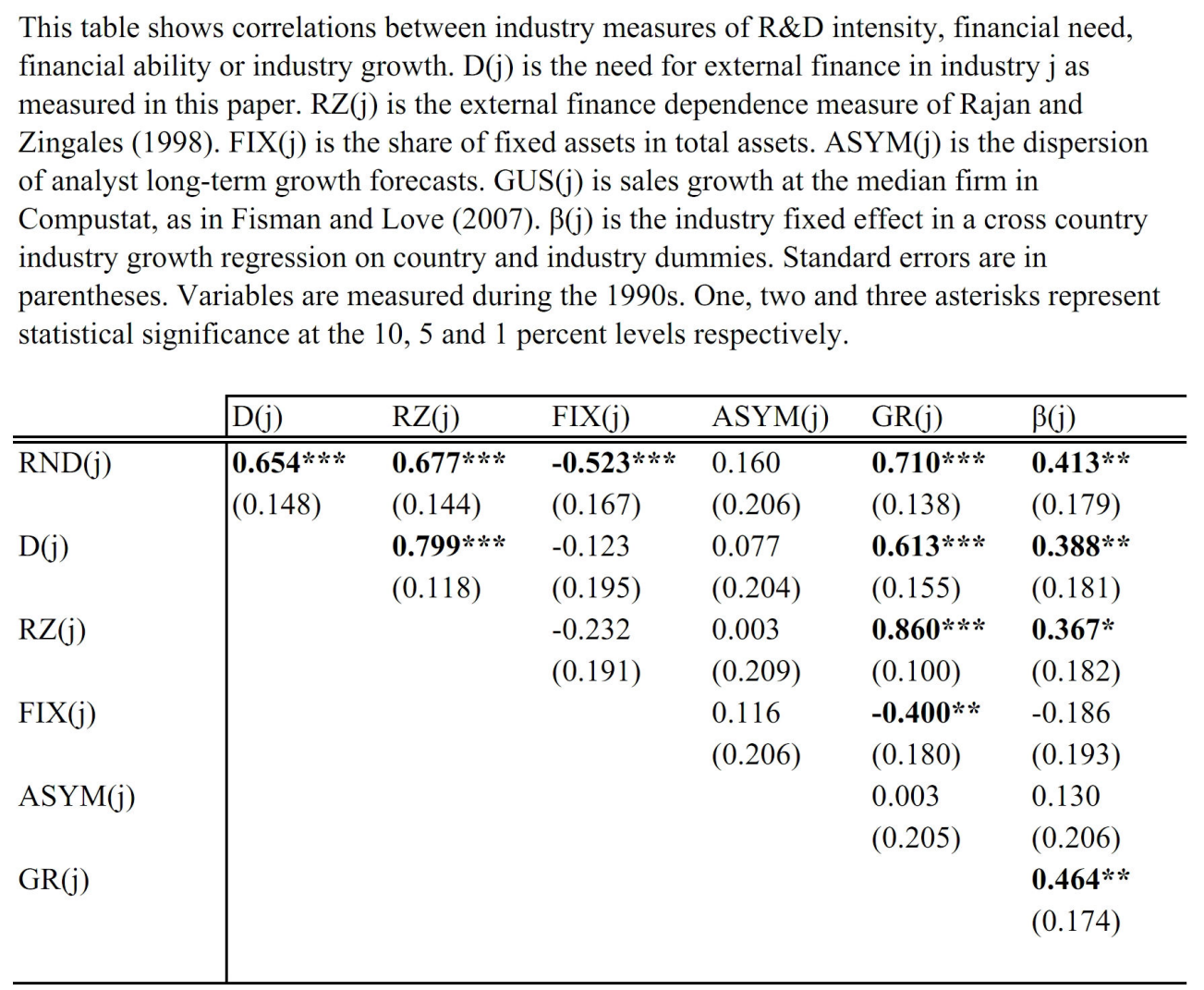

We compute R\&D intensity for the industry breakdown of Jorgenson et al (2007), which is finer than that in INDSTAT3. ${ }^{2}$ This allows us to compare R\&D intensity with the Jorgenson et al (2007) TFP growth numbers. The correlation between $R N D_{j}$ and TFP growth is 0.39 and the correlation between $R N D_{j}$ and industry growth is 0.47 , both of which are significant at the 1 percent level. This finding supports our focus on the parameter range over which R\&D intensity and productivity growth are positively related, as per Lemma 1.

\footnotetext{
${ }^{2}$ For these purposes we measure R\&D intensity over the entire post-war era, just as the Jorgenson et al (2007) numbers. We lose 12 industries because no firms in Compustat report the corresponding industry codes for their classification.
} 
6. On the value of $\varepsilon$ : Equation (15) indicates that, in the benchmark economy, $\varepsilon$ equals one plus the coefficient obtained from regressing value added growth on TFP growth in the benchmark economy. Thus, we can estimate $\varepsilon$ from the Jorgenson et al (2007) data. Using all industries, we find that $\varepsilon=3.21$ (s.d. 0.167 ), or $\varepsilon=2.08$ (s.d. 0.176) if we exclude two outliers. Among 32 manufacturing industries, the estimate is $\varepsilon=3.75$ (s.d. 0.125 ), and using 44 services and other industries it is $\varepsilon=1.85$ (s.d. 0.355). In all cases, the estimate is significantly greater than unity.
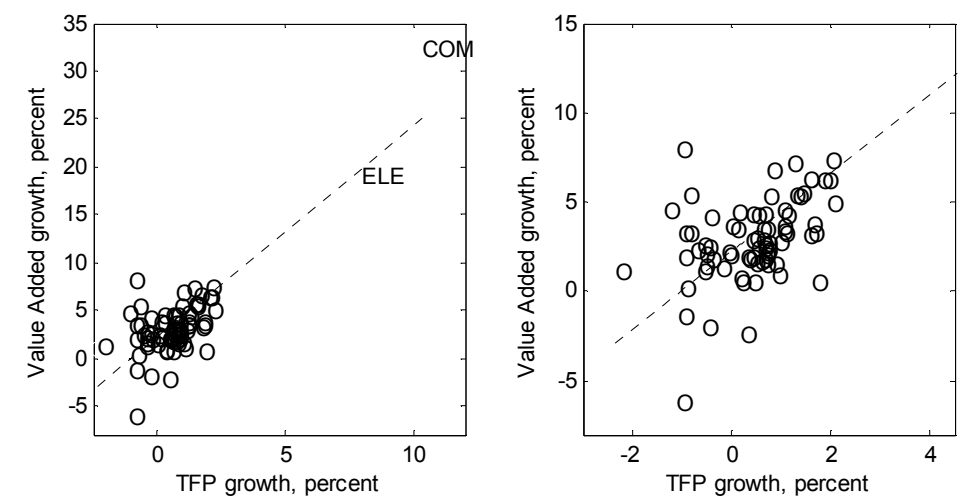

Figure $A 2$ - Value-added growth and TFP growth across industries over the post-war era in the United States. The panel on the right omits two outliers (Computing equipment and electrical machinery. Dotted lines are least-squares fitted values. Source - Jorgenson et al (2007).

What are the quantitative implications of these values for $\varepsilon$ ? Ilyina and Samaniego (forthcoming) find that $\beta_{F, R N D}=0.038$ in the 1990s. The country at the 75 th percentile of financial development (credit-to-GDP ratio) is France, whereas Egypt is at the 25th. The industry at the 75th percentile of $R N D_{j}$ is Industrial Chemicals, and Food Products is at the 25th. If financial development in an average country were to improve from the level of Egypt to the level of France, Industrial Chemicals would grow 1.1\% faster annually than Food Products. If $\varepsilon=3.75$, then this $1.1 \%$ growth differential reflects an additional $0.4 \%$ productivity growth differential due to financial development.

A value of $\varepsilon$ not only translates between the empirical interaction coefficients and industry productivity differences. If financial development results in no technological regress in any industry, then it also translates into a lower bound on the productivity gain from a given increase in financial development. ${ }^{3}$ Suppose, for example, that financial development were

\footnotetext{
${ }^{3}$ Since there exist industries with little $\mathrm{R} \& \mathrm{D}$, little external finance and little technical change (e.g. Tobacco, ISIC code 314) then this lower bound may in fact be a reasonable estimate of the productivity impact of financial development.
} 
to improve in all countries in the Ilyina and Samaniego (forthcoming) sample to the highest level among countries in the sample (Japan). Adding across all industries in each country using the industry shares reported in INDSTAT3, ${ }^{4}$ and assuming that in absolute terms no industry deteriorates in terms of productivity growth, this implies that increasing the level of financial development to that of the most developed economy raises manufacturing productivity by between $0.5 \%$ and $1.5 \%$ annually depending on the initial level of financial development, with a median of $0.9 \%$. According to the BEA, US productivity growth this decade has averaged $2.6 \%$, so these numbers are economically significant.

\section{Cross-country industry growth regressions}

We estimate equation (16). This is the differences-in-differences specification in Ilyina and Samaniego (2010), except that there are several additional second order terms suggested by the Taylor approximation in the paper.

For these purposes, we also need to select a measure of initial conditions $a_{j k}$. We report results using the industry share of manufacturing as in RZ: however, results were similar using other measures, such the difference between the industry share in country $k$ and the industry share in the US.

Results using financial deepening as a measure of financial development are reported in Table $B 4$. We report heteroskedasticity-consistent standard errors. The upshot is that there is a strong, significant interaction between R\&D intensity and financial development. This result is robust to using different measures of financial development. ${ }^{5}$ For robustness, we also repeat the regression with industry indicators, country financial development (as measured by $C R E$ ), and country-industry growth data measured during the 1980s instead of the 1990s, finding the same results.

Regarding the other terms in the regressions, it is interesting that $\beta_{z}<0$ and $\beta_{z^{2}}>0$, consistent with a trend towards a uniform industry structure across countries. The remaining interaction terms $\beta_{R N D, z}, \beta_{A, z}$ and $\beta_{F, z}$ are generally not significant and are of unstable sign.

\footnotetext{
${ }^{4}$ As discussed in Jorgenson et al (2007) the way to aggregate productivity is using Domar weights, not shares of value added. We compute Domar weights assuming that industry value added equals half of gross output: see Ngai and Samaniego (2009).

${ }^{5}$ We also obtained these results when measuring $R \& D$ intensity as the average research spending divided by net sales as reported by the National Science Foundation, and also the median R\&D intensity divided by sales in Compustat.
} 
Table A3 -- Interaction of R\&D intensity with financial development in country-industry growth regressions.

This table presents the panel regression estimation results of equation (24). The dependent variable is the growth rate of industry $\mathrm{j}$ in country $\mathrm{k}$. RND(j) is the R\&D intensity of industry $\mathrm{j}$; FinDev(k) is financial development in country $\mathrm{k} ; \mathrm{z}(\mathrm{j}, \mathrm{k})$ is a measure of technology gap for industry $\mathrm{j}$ located in country $\mathrm{k}$. Country and industry dummies are omitted for brevity. Standard errors are reported in parentheses. Standard errors are corrected for heteroskedasticity using the method of White (1980). Financial development is measured in five ways: CRE is private credit/GDP; MARG is the interest rate margin; BANK is the ratio of bank overhead to assets; ACCS is access to credit as measured using a survey of executives; and SOPH is the sophistication of the financial system as measured using a survey of executives. CRE80 is CRE measured in the 1980s, all other variables are measured in the 1990s. Sources: IMF, Compustat, UNIDO, Beck et al (2002), World Economic Forum (2008). Standard errors are in parentheses. One, two and three asterisks represent statistical significance at the 10,5 and 1 percent levels respectively.

\begin{tabular}{|c|c|c|c|c|c|c|}
\hline Regression specification & CRE & MARG & BANK & ACCS & SOPH & CRE80 \\
\hline$\overline{R N D}(\mathrm{j}) \times$ FinDev $(\mathrm{k})$ & $\begin{array}{l}\mathbf{0 . 0 4 6 * * *} \\
(0.018)\end{array}$ & $\begin{array}{l}\mathbf{0 . 0 6 4 * * *} \\
(0.020)\end{array}$ & $\begin{array}{l}\mathbf{0 . 0 7 9} * * * \\
(0.019)\end{array}$ & $\begin{array}{l}\mathbf{0 . 0 6 2} * * * \\
(0.022)\end{array}$ & $\begin{array}{l}\mathbf{0 . 0 5 9} * * * \\
(0.022)\end{array}$ & $\begin{array}{l}\mathbf{0 . 0 4 7 * * *} \\
(0.018)\end{array}$ \\
\hline $\mathrm{RND}(\mathrm{j}) \times \mathrm{z}(\mathrm{j}, \mathrm{k})$ & $\begin{array}{l}0.681 \\
(0.696)\end{array}$ & $\begin{array}{l}0.492 \\
(0.682)\end{array}$ & $\begin{array}{l}0.490 \\
(0.672)\end{array}$ & $\begin{array}{l}\mathbf{1 . 4 5 *} \\
(0.835)\end{array}$ & $\begin{array}{l}\text { 1.41* } \\
(0.844)\end{array}$ & $\begin{array}{l}1.37^{* * *} \\
(0.646)\end{array}$ \\
\hline $\mathrm{z}(\mathrm{j}, \mathrm{k}) \times$ FinDev $(\mathrm{k})$ & $\begin{array}{l}-0.825 \\
(0.611\end{array}$ & $\begin{array}{l}0.038 \\
(0.934)\end{array}$ & $\begin{array}{l}0.108 \\
(0.425)\end{array}$ & $\begin{array}{l}0.640 \\
(0.441)\end{array}$ & $\begin{array}{l}\mathbf{0 . 9 3 1} \text { ** } \\
(0.462)\end{array}$ & $\begin{array}{l}-0.367 \\
(0.464)\end{array}$ \\
\hline $\mathrm{z}(\mathrm{j}, \mathrm{k})$ & $\begin{array}{l}-\mathbf{4 . 3 4} * * * \\
(0.923)\end{array}$ & $\begin{array}{l}-\mathbf{3 . 9 8} * * * \\
(0.934)\end{array}$ & $\begin{array}{l}-\mathbf{3 . 9 9} * * * \\
(0.936)\end{array}$ & $\begin{array}{l}-\mathbf{5 . 9 1} * * * \\
(1.15)\end{array}$ & $\begin{array}{l}-6.10 * * * * \\
(1.15)\end{array}$ & $\begin{array}{l}-\mathbf{3 . 2 9} * * * \\
(0.464)\end{array}$ \\
\hline $\mathrm{z}(\mathrm{j}, \mathrm{k})^{2}$ & $\begin{array}{l}13.2 * * * \\
(4.91)\end{array}$ & $\begin{array}{l}13.6 * * * * \\
(5.03)\end{array}$ & $\begin{array}{l}13.6 * * * \\
(5.03)\end{array}$ & $\begin{array}{l}19.2 * * * \\
(5.50)\end{array}$ & $\begin{array}{l}18.9 * * * \\
(5.24)\end{array}$ & $\begin{array}{l}7.23 * \\
(4.31)\end{array}$ \\
\hline$\overline{\mathrm{R}^{2}}$ & 0.305 & 0.307 & 0.308 & 0.305 & 0.306 & 0.391 \\
\hline Obs & 968 & 968 & 968 & 699 & 699 & 1084 \\
\hline
\end{tabular}

\section{Model Extensions}

\section{A Multiple limiting industries}

The long-run behavior of the model depends on the fact that one industry grows to dominate the economy as $t \rightarrow \infty$. However, it is straightforward to extend the model to allow several industries to persist in the limit (as opposed to just one). For example, suppose that the set of $J$ industries is split into $N \geq 1$ disjoint sectors (e.g. manufacturing and services), $\left\{J_{1}, \ldots, J_{N}\right\}$, where $\cup_{n=1}^{N} J_{N}=J$. Let agents have the following preferences:

$$
c_{t}=\left[\prod_{n=1}^{N} \frac{c_{n t}}{\eta_{n}}\right]^{\eta_{n}}, \sum_{n=1}^{N} \eta_{n}=1,
$$

where

$$
c_{n t}=\left[\sum_{j \in J_{n}} \xi_{j}^{n} c_{j t}^{\frac{\varepsilon_{n}-1}{\varepsilon_{n}}}\right]^{\frac{\varepsilon_{n}}{\varepsilon_{n}-1}}, \sum_{j \in J_{n}} \xi_{j}^{n}=1 \forall n .
$$


Preferences over consumption of goods within each sector are of the same form as (1), and consumption of the sectorial goods is aggregated using a Cobb-Douglas function. Then, our analysis applies in this context to each sector. As a result, the limiting structure of an economy without financing constraints would feature $N$ industries. The share of GDP of each sector is constant over time and equal to $\eta_{n}$, but there would be structural change within each sector. If $\varepsilon_{n}>1 \forall n$, then the limiting industry within each sector would be the industry with the highest rate of frontier productivity growth. For example, if we interpret broad sectors in terms of manufacturing vs. services, we will see that the evidence supports $\varepsilon_{n}>1$ within manufacturing and within services. For this environment, Proposition 5 would continue to hold among industries within the same sector, and regressions (16) and (17) would apply to industries within a sector.

Many industrialized countries feature a steadily increasing service sector share, which Ngai and Pissarides (2007) account for on the basis that manufacturing and services are imperfect substitutes and that technical progress in services is slower than in manufacturing. This can be accounted for within the model by generalizing (1) to a CES structure in which broad sectors are imperfect substitutes. In that case, the less productive, less R\&D intensive service sector would grow over time, but within sectors the most productive service industry, manufacturing industry, etc. would gradually grow to dominate. However, if the highest value of $g_{j}$ within services exceeds that within manufacturing, then the pattern might be reversed at some point. Thus, convergence dynamics in such an environment could display some additional complexity.

\section{B Equilibria in which $N_{t}^{E}>N_{t}^{R}$}

We have focused on parameters under which entrepreneurs are on the short end of the market in equilibrium $\left(N_{t}^{E} \leq N_{t}^{R}\right)$. In this case, the value of starting a firm is constant over time and across industries. Since the entrepreneur's share of profits is constant too, changes over time in relative prices equal inverse changes in relative productivities. If $N_{t}^{E}>N_{t}^{R}$, then some of the equilibrium ex-post returns from $R \& D$ would accrue to entrepreneurs. Let us refer to this possibility as "research pass-through." With research pass-through, changes over time in goods prices would reflect both changes over time in productivity and (to some extent) changes over time in the returns to R\&D. This would also be true if we had a single agent both creating firms and conducting research, rather than distinguishing between entrepreneurs and researchers. For a given $R \& D$ expenditure, profits are higher in $R \& D$ intensive industries (lower $\kappa_{j}$ ) as the rate of success $\mu_{j t}$ is higher for a given amount of R\&D spending. Also, for a given change in $\mathrm{R} \& \mathrm{D}$ expenditure (resulting from a loosening of financing constraints), 
profits will increase more in R\&D intensive industries, caeteris paribus. Since prices adjust so that entrepreneurs are indifferent between industries, research pass-through implies that $\mathrm{R} \& \mathrm{D}$ intensive industries display disproportionately large declines in their output prices in financially developed economies. Hence, allowing for research pass-through should strengthen the results in Proposition ??, as relaxing financial constraints would once again particularly cheapen goods in research-intensive industries. While research pass-through is a phenomenon of interest, its presence renders the model no longer analytically tractable and we leave its analysis for future work.

\section{Stages of Diversification}

To further illustrate the implications of delayed structural change, consider the following well-known feature of developing economies. Imbs and Wacziarg (2003) and Koren and Tenreyro (2007) find that, as countries grow, specialization tends to decrease until a certain point, after which specialization increases once more. The model economy is capable of displaying this pattern. Consider a less financially developed economy that starts out relatively undiversified, perhaps specializing in certain industries as a result of initial resource or knowledge endowments. If these are industries other than those that would eventually grow to dominate the economy, there may be a "U" shaped specialization pattern over time. Figure $A 3$ represents industry specialization in a simple parameterization of the model that displays this U-shape for two 3-sector economies that are initially dominated by the slowest-growing industry, ${ }^{6}$ and that differ only in terms of $F_{k}$. The impact of financial underdevelopment is to slow the process of productivity-driven structural change, leading to a delayed turning point.

In general this result may not obtain, as for a large number of industries specialization patterns could potentially be complex. However, when there are two industries the result can be shown. Define "specialization" as the coefficient of variation in industry shares i.e. the standard deviation of industry shares divided by the mean. This is one of the benchmark measures used in Imbs and Wacziarg (2003). If $s_{j t}$ is the share of industry $j$, then "specialization" $S_{t}$ equals

$$
S_{t} \equiv \frac{\sqrt{\left(s_{1 t}-0.5\right)^{2}+\left(s_{2 t}-0.5\right)^{2}}}{0.5}=\sqrt{2}\left\|2 s_{1 t}-1\right\| .
$$

Now suppose that $g_{1}<g_{2}$, and $F$ is such that neither industry is in Region 3 (i.e. there

\footnotetext{
${ }^{6}$ This is the same parameterization as in Figure 1, except that initial conditions are more skewed towards the industry with the lowest value of $g_{j}$.
} 
is convergence in productivity growth rates). Then, if $\varepsilon>1$, for sufficiently low $a_{1,0}$ the economy will start off specialized in industry 1 whereas in all periods thereafter the share of 2 will increase. Thus, for a time, specialization $S_{t}$ will decrease, until $s_{1 t}$ drops below half - after which specialization will begin increasing again. For lower $F$, differences in industry productivity growth rates are smaller (Proposition 5), so the rate at which $s_{1 t}$ declines will be slower, and the date at which the turning point in specialization appears will be later. ${ }^{7}$

The pattern of "stages of diversification" is typically interpreted in terms of the diversification of productive risk in a small open economy - see Koren and Tenreyro (2007) for an extensive discussion. The model shows that even a closed economy without aggregate uncertainty may display this pattern. Moreover, the positive interaction coefficients in RZ, Fisman and Love (2007) and Ilyina and Samaniego (forthcoming) can be interpreted as indicating that financial underdevelopment slows the transition across stages of diversification, and the process of specialization during the final stage.

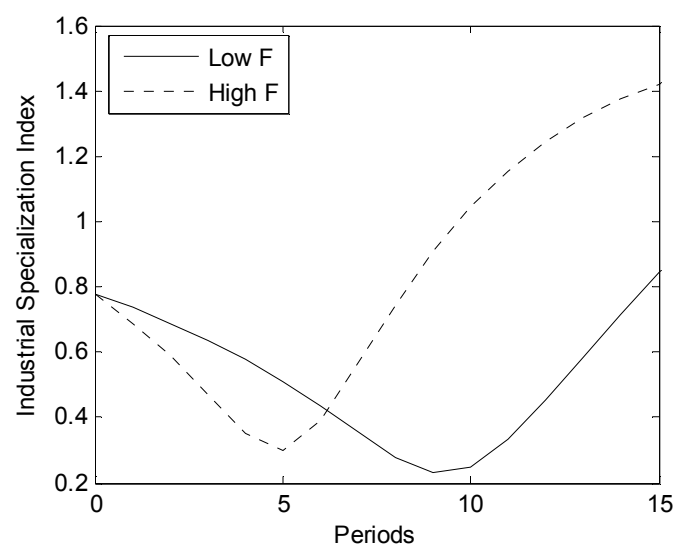

Figure $A 3$ - Patterns of industrial specialization along the growth path.

The index of specialization is the coefficient of variation among industry shares of GDP, as in Imbs and Wacziarg (2003). The coefficient of variation is defined as the standard deviation divided by the mean.

Figure $A 3$ is based on the economy in Figure 1, which is not based on a careful calibration and which only has 3 industries. However, Figure $A 4$ shows that even for large $N$ and for realistic parameter values (i.e. in the calibrated economy), a U-shaped specialization pattern is observed, at least for some countries.

\footnotetext{
${ }^{7}$ If $\varepsilon<1$, for sufficiently low $a_{2,0}$ the economy will start off specialized in industry 2 whereas in all periods thereafter the share of 1 will increase, and the same dynamics obtain.
} 

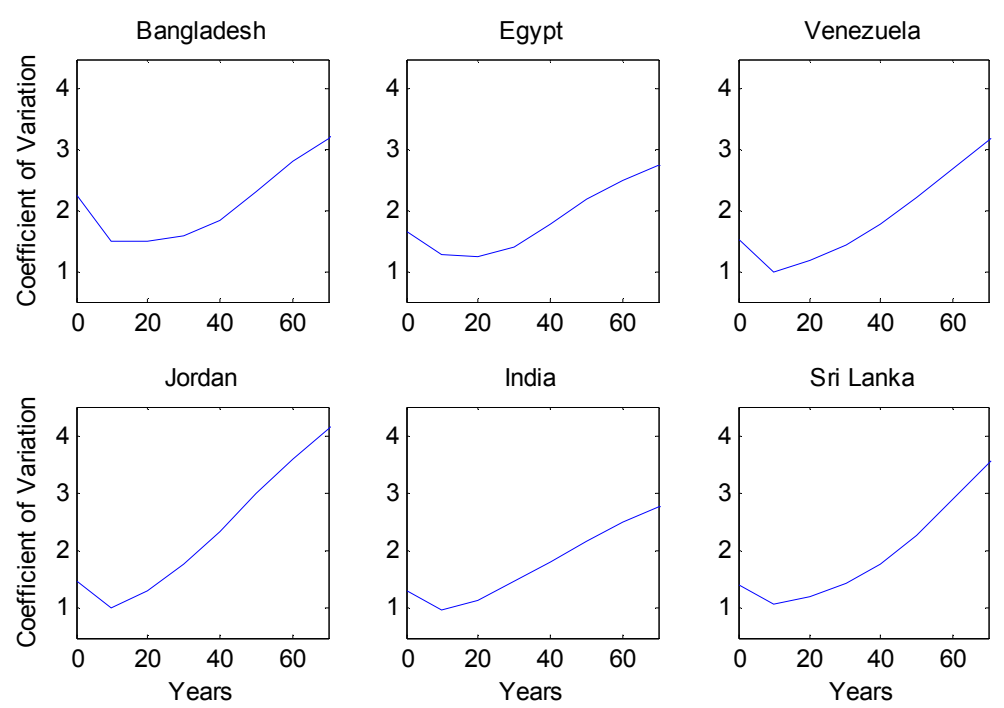

Figure $A 4$ - Patterns of industrial specialization along the growth path, for selected countries in the model economy. Results are reported assuming that financial development accounts for one third of crosscountry differences in R\&D intensity, and that the productivity gap in the benchmark industry between the most and least financially developed economies is $25 \%$. The index of specialization is the coefficient of variation among industry shares of GDP, as in Imbs and Wacziarg (2003). The coefficient of variation is defined as the standard deviation of industry shares, divided by the mean.

Figure $A 3$ would suggest that more financially developed economies should become specialized more rapidly than other economies. We examined whether there was a link in the calibrated model between changes over time in broad measures of specialization and financial development. We measured the coefficient of variation among industry shares of manufacturing for each country in the data, and then measured the same coefficient one period later in the model economy. We found that changes in specialization were not significantly correlated with $F_{k}$ as measured by matching country R\&D intensity. When productivity in Textiles is the same across countries, the correlation between changes in specialization and $F$ is 0.12 . and insignificant. When the most and least financially developed economies differ by about 0.5 in textile productivity, this correlation is -0.15 : the sign is the opposite of that suggested in Figure $A 3$. The reason is simply that, as productivity gaps between countries 
increase, industry growth speeds up (recall concavity of the function $H_{j}^{2}$, the productivity growth locus of a constrained industry). This indicates the importance of initial conditions for identifying the impact of $F$ on industry outcomes and structural change.

\section{Aggregate implications}

We conclude by briefly examining the aggregate implications of these industry results. It should be noted that we have only calibrated the manufacturing sector in the model economy: nonetheless, the results should be robust provided the most R\&D intensive nonmanufacturing industries are not as R\&D intensive as, say, Chemicals or Machinery.

The main aggregate implication of the model economy is that it sorts countries into those that converge in growth rates, in income levels, or neither. Countries converge in income levels if the most $R \& D$ intensive industries lie in Region 1 of parameter space, so that the industries that grow to dominate the economy as a result of productivity-driven structural change are not constrained in the long run. Countries converge in growth rates (but not levels) if the most R\&D-intensive industries lie in Region 2 of parameter space, so they are constrained in the long run but not so severely that they fall progressively farther behind the frontier.

For the preferred parameterization, Table $A 4$ shows the industry-country pairs that lie in Region 2 - i.e. they are constrained in terms of productivity levels. ${ }^{8}$ Other Chemicals (ISIC 352, primarily pharmaceuticals) and Professional and Scientific Equipment (ISIC 385) are the most $R \& D$ intensive industries in our classification, and they lie in Region 2 in all countries. In some countries, financing limits are such that Non-electrical Machinery (ISIC 382) and Electrical Machinery (ISIC 383) also lie in Region 2. The other 24 manufacturing industries all lie in Region 1 in all countries. Thus, the model suggests that all countries in the data set lie in a development trap, although it is "shallow" in the sense that very few industries are constrained in the long run. Interestingly, no industry-country pairs lie in Region 3, indicating that no countries lie in a development sink. This suggests long-run convergence in growth rates across all economies - and that differences in levels due to the long-term impact of financial development are likely to be small.

\footnotetext{
${ }^{8}$ Results are very similar for other parameterizations, except those in which financial development accounts for almost all differences across countries in R\&D spending. In those cases, many more countries and industries are constrained: however, those parameterizations do not appear as empirically relevant due to the small magnitude of the interaction coefficient.
} 


\begin{tabular}{|c|c|c|c|c|c|}
\hline \multicolumn{6}{|c|}{$\begin{array}{l}\text { This table shows the industry-country pairs that are in Region } 2 \text { in the calibra } \\
\text { cconomy. Region } 2 \text { indicates industrios that arc level-constraincd: their produ } \\
\text { growth rate converges to the frontier productivity growth rate, but credit cons } \\
\text { are such that they may be permancently bounded away from } \mathrm{a}^{*} \text {. Results are re } \\
\text { for the economy in which } 32 \% \text { of country differences in R\&D intensity are ac } \\
\text { for by financing constraints. }\end{array}$} \\
\hline & $\begin{array}{l}\text { Ouher } \\
\text { chemicals }\end{array}$ & $\begin{array}{l}\text { Machincry } \\
\text { (not elec) }\end{array}$ & $\begin{array}{l}\text { Machincry } \\
\text { (elec) }\end{array}$ & $\begin{array}{l}\text { Pror/sci } \\
\text { equip }\end{array}$ & $\mid \begin{array}{l}F k \\
\text { in the } \\
\text { model }\end{array}$ \\
\hline Isracl & $\mathrm{x}$ & & & $\frac{1}{x}$ & 0.8126 \\
\hline Finland & $x$ & & & $x$ & 0.4742 \\
\hline Bclgium & $\mathrm{x}$ & $\mathrm{X}$ & & $\mathrm{x}$ & 0.4429 \\
\hline Swedenl & $\mathrm{x}$ & $x$ & & $x$ & 0.427 \\
\hline Norway & $\mathrm{x}$ & $\mathrm{x}$ & & $x$ & 0.3921 \\
\hline Dcnmark & $\mathrm{x}$ & $\mathrm{x}$ & & $\mathrm{x}$ & 0.3817 \\
\hline Australia & $x$ & $x$ & & $x$ & 0.3559 \\
\hline Canada & $\mathrm{x}$ & $\mathrm{X}$ & & $\mathrm{X}$ & 0.7363 \\
\hline Austria & $\mathrm{x}$ & $\mathrm{x}$ & & $\mathrm{x}$ & 0.3052 \\
\hline France & $\mathrm{x}$ & $x$ & & $x$ & 0.2971 \\
\hline Nethcrlants & $\mathrm{x}$ & $\mathrm{x}$ & $x$ & $\mathrm{x}$ & 0.2882 \\
\hline Japan & $\mathrm{x}$ & $x$ & $\mathrm{x}$ & $x$ & 0.286 \\
\hline Korea & $x$ & $x$ & $\mathrm{x}$ & $x$ & 0.2852 \\
\hline UK & $\mathrm{x}$ & $\mathrm{X}$ & $x$ & $\mathrm{x}$ & 0.2625 \\
\hline Germany & $\mathrm{x}$ & $x$ & $\mathrm{x}$ & $x$ & 0.2624 \\
\hline New Zealland & $\mathrm{x}$ & $x$ & $\mathrm{x}$ & $x$ & 0.2575 \\
\hline Jordan & $\mathrm{x}$ & $\mathrm{x}$ & $x$ & $\mathrm{x}$ & 0.252 \\
\hline Singapore & $\mathrm{x}$ & $x$ & $\mathrm{x}$ & $x$ & 0.2467 \\
\hline Spain & $\mathrm{x}$ & $\mathrm{x}$ & $x$ & $\mathrm{x}$ & 0.2365 \\
\hline Kenya & $\mathrm{x}$ & $\mathrm{X}$ & $\mathrm{x}$ & $\mathrm{x}$ & 0.2327 \\
\hline Zinibabwe & $\mathrm{x}$ & $\mathrm{x}$ & $\mathrm{x}$ & $x$ & 0.2303 \\
\hline India & $\mathrm{x}$ & $\mathrm{x}$ & $\mathrm{x}$ & $\mathrm{x}$ & 0.2299 \\
\hline Italy & $\mathrm{x}$ & $\mathrm{x}$ & $\mathrm{x}$ & $x$ & 0.2291 \\
\hline Bangladesh & $\mathrm{x}$ & $\mathrm{x}$ & $x$ & $\mathrm{x}$ & 0.2273 \\
\hline Porlugal & $\mathrm{x}$ & $\mathrm{X}$ & $x$ & $\mathrm{X}$ & 0.2264 \\
\hline Greece & $\mathrm{x}$ & $\mathrm{x}$ & $\mathrm{x}$ & $\mathrm{x}$ & 0.2249 \\
\hline Moroсcо & $x$ & $\mathrm{X}$ & $x$ & $\mathrm{x}$ & 0.223 \\
\hline Brazil & $\mathrm{x}$ & $\mathrm{x}$ & $\mathrm{x}$ & $x$ & 0.2225 \\
\hline South Africa & $x$ & $\mathrm{x}$ & $\mathrm{x}$ & $x$ & 0.2224 \\
\hline Chile & $\mathrm{x}$ & $\mathrm{x}$ & $x$ & $\mathrm{x}$ & 0.2217 \\
\hline Turkey & $\mathrm{x}$ & $\mathrm{x}$ & $\mathrm{x}$ & $\mathrm{x}$ & 0.2195 \\
\hline Malaysia & $x$ & $\mathrm{X}$ & $x$ & $\mathrm{X}$ & 0.2194 \\
\hline Mexico & $\mathrm{x}$ & $\mathrm{x}$ & $\mathrm{x}$ & $\mathrm{x}$ & 0.2157 \\
\hline Costa Riea & $\mathrm{x}$ & $\mathrm{x}$ & $\mathrm{x}$ & $\mathrm{x}$ & 0.215 \\
\hline Pakisian & $\mathrm{x}$ & $\mathrm{x}$ & $x$ & $\mathrm{x}$ & 0.21 .33 \\
\hline Veneziela & $\mathrm{x}$ & $x$ & $\mathrm{x}$ & $\mathrm{x}$ & 0.2116 \\
\hline Egrpt & $\mathrm{x}$ & $\mathrm{x}$ & $\mathrm{x}$ & $\mathrm{x}$ & 0.2114 \\
\hline Colombia & $\mathrm{x}$ & $\mathrm{x}$ & $x$ & $\mathrm{x}$ & 0.2113 \\
\hline Sri Lanka & $\mathrm{x}$ & $\mathrm{x}$ & $\mathrm{x}$ & $\mathrm{x}$ & 0.2111 \\
\hline Peru & $\mathrm{x}$ & $\mathrm{x}$ & $\mathrm{x}$ & $\mathrm{x}$ & 0.2099 \\
\hline Philippines & $x$ & $x$ & $\mathrm{x}$ & $x$ & 0.2093 \\
\hline
\end{tabular}

Table $A 4$ - Country-industry pairs in the calibrated economy which are in Region 2. Region 2 indicates industries that are level-constrained, and are permanently bounded away from $a_{j}^{*}$. Such industries are marked "X". Results correspond to the preferred parameterization. No country-industry pairs were found to be in Region 3 for any parameterization. Countries are ordered according to their calibrated levels of $F_{k}$. 


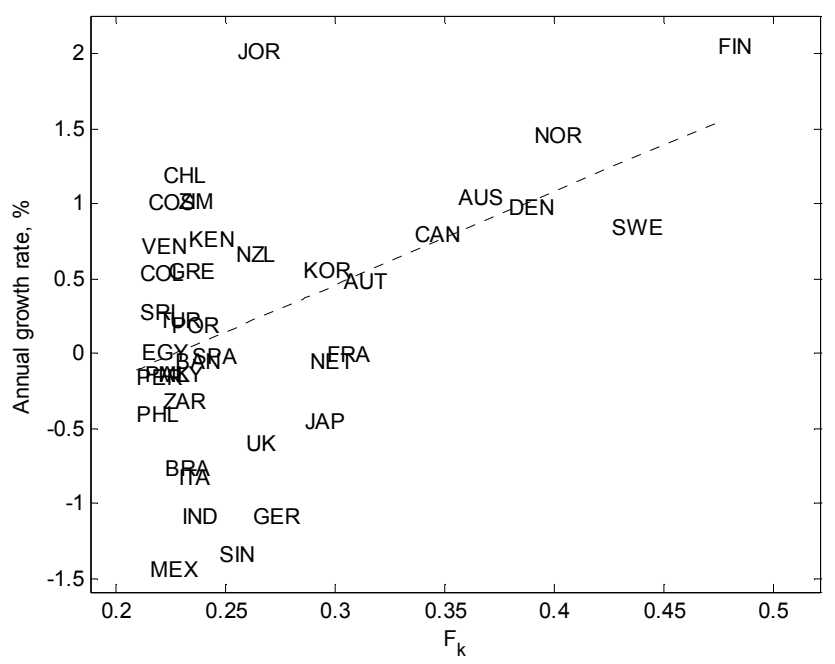

Figure $A 5$ - Financial development and aggregate growth in the calibrated model economy. Aggregate growth values are rescaled so that the median growth rate is zero, as growth in the model is defined with respect to the wage making it difficult to compare directly with the data. The dashed line represents fitted values, excluding Israel. Belgium and Morocco are also excluded because the reported industry shares cover $68 \%$ and $78 \%$ of manufacturing output respectively. The next lowest (Mexico) is over $93 \%$.

In transition, aggregate growth in the model economy results from the interaction of industry composition with the calibrated financing constraints. The model predicts that, given initial conditions, the least financially constrained economies should grow faster. However, since the most financially constrained economies are also likely to be technologically backward, this leads them to grow faster caeteris paribus. Thus, there are opposing effects of finance on growth. However, in our preferred calibration (excluding Israel), ${ }^{9}$ we find that the correlation between manufacturing growth and $F_{k}$ in the preferred parameterization is $0.49^{* * *}$ (s.d. 0.146). See Figure $A 5$.

It is worth mentioning that we also estimated the regression specification derived in

\footnotetext{
${ }^{9}$ Israel is excluded because it is an outlier in R\&D intensity, and hence in $F_{k}$. Belgium and Morocco are also excluded because the reported industries cover only $68 \%$ and $78 \%$ of manufacturing output respectively. The next lowest is Mexico with over $93 \%$ coverage.
} 
AHM for a one-sector economy, using model-generated GDP growth values. Their simplest specification can be reduced to:

$$
G_{k}=C+\beta_{G, F} G D P_{k} \times F_{k}+\beta_{G} G D P_{k}+\epsilon_{k}
$$

where $G_{k}$ is GDP growth, $C$ is a constant, $G D P_{k}$ is aggregate output (interpreted as a measure of aggregate initial conditions) and $F_{k}$ is a measure of financial development. Their

model predicts that $\beta_{G, F}>0$. We estimated this regression using model-generated values of $F_{k}$ and $G_{k}$, drawing $G D P_{k}$ from the World Development Indicators, and excluding Belgium and Morocco as explained above (excluding Israel did not make much difference in this case). We found a statistically significant coefficient $\beta_{G, F}$, as predicted in their paper (coefficient $0.38^{* *}$, s.d. 0.140). Thus, the predictions of the related one-sector model of Aghion et al (2005) continue to hold in our calibrated, multisector model. Nonetheless, even if crosscountry growth regressions were inconclusive as far as identifying an impact of financial development on aggregate growth is concerned - as a result of differences in industry composition or of differences in the impact of finance across industries - the model suggests that differences-in-differences regressions are an appropriate method for identifying this impact, as originally proposed by Rajan and Zingales (1998).

\section{References}

Imbs, Jean and Romain Wacziarg, 2003, "Stages of Diversification," American Economic Review, Vol. 93 No. 1, pp. 63-86.

Koren, Miklós and Silvana Tenreyro, 2007, "Volatility and Development," Quarterly Journal of Economics, Vol. 122 No. 1, pp. 243-287. 